\title{
Targeting $\beta 2$-Adrenergic Receptors Shows Therapeutical Benefits in Clear Cell Renal Cell Carcinoma from Von Hippel-Lindau Disease
}

\author{
Virginia Albiñana ${ }^{1,2}$, Eunate Gallardo-Vara ${ }^{1,2, \dagger}$, Isabel de Rojas-P ${ }^{1}$, Lucia Recio-Poveda ${ }^{1,2}$, \\ Tania Aguado 1, $\neq\left(\mathbb{D}\right.$, Ana Canto-Cano ${ }^{1}$, Daniel T. Aguirre ${ }^{3}$, Marcelo M. Serra ${ }^{4} \mathbb{D}$, \\ Pilar González-Peramato ${ }^{5}$, Luis Martínez-Piñeiro ${ }^{6}$, Angel M. Cuesta ${ }^{1,2, * \mathbb{D}}$ and \\ Luisa Maria Botella 1,2,*(D) \\ 1 Centro de Investigaciones Biológicas Margarita Salas, Consejo Superior de Investigaciones Científicas (CSIC), \\ 9 Ramiro de Maeztu Street, 28050 Madrid, Spain; vir_albi_di@yahoo.es (V.A.); \\ eunate.gallardo@yale.edu (E.G.-V.); iderojas@ucm.es (I.d.R.-P.); lrecio@cib.csic.es (L.R.-P.); \\ tania.aguado@gmail.com (T.A.); anadelcantocano@gmail.com (A.C.-C.) \\ 2 Centro de Investigación Biomédica en Red de Enfermedades Raras (CIBERER), Group U707, \\ 3-5 Monforte de Lemos Avenue, 28029 Madrid, Spain \\ 3 Department of Neurosurgery, Hospital Universitario Fundación Jiménez Díaz (IIS-FJD), \\ 2 Reyes Católicos Avenue, 28040 Madrid, Spain; dtaguirre@fjd.es \\ 4 Department of Internal Medicine, Hospital Italiano de Buenos Aires (HIBA), 4190 Pres. Tte. Gral. Juan \\ Domingo Perón Avenue, C1199 Ciudad Autónoma de Buenos Aires, Argentina; \\ marcelo.serra@hospitalitaliano.org.ar \\ 5 Department of Pathology, Instituto de Investigación IdiPaz. 6 Pedro Rico Street, 28029 Madrid, Spain; \\ mpilar.gonzalezperamato@salud.madrid.org \\ 6 Department of Urology, Instituto de Investigación IdiPaz, 6 Pedro Rico Street, 28029 Madrid, Spain; \\ luis.mpineiro@salud.madrid.org \\ * Correspondence: acme@cib.csic.es (A.M.C.); cibluisa@cib.csic.es (L.M.B.) \\ + Yale Cardiovascular Research Center, Section of Cardiovascular Medicine, Department of Internal Medicine, \\ Yale University School of Medicine, 300 George Street, New Haven, CT 06511, USA. \\ $\ddagger$ Department of Biochemistry and Molecular Biology, Faculty of Biology, Complutense University Madrid, \\ 12 José Antonio Novais Street, 28040 Madrid, Spain.
}

Received: 18 June 2020; Accepted: 21 August 2020; Published: 25 August 2020

check for updates

\begin{abstract}
Von Hippel-Lindau (VHL), is a rare autosomal dominant inherited cancer in which the lack of VHL protein triggers the development of multisystemic tumors such us retinal hemangioblastomas (HB), CNS-HB, and clear cell renal cell carcinoma (ccRCC). ccRCC ranks third in terms of incidence and first in cause of death. Standard systemic therapies for VHL-ccRCC have shown limited response, with recurrent surgeries being the only effective treatment. Targeting of $\beta 2$-adrenergic receptor (ADRB) has shown therapeutic antitumor benefits on VHL-retinal HB (clinical trial) and VHL-CNS HB (in vitro). Therefore, the in vitro and in vivo antitumor benefits of propranolol (ADRB-1,2 antagonist) and ICI-118,551 (ADRB-2 antagonist) on $\mathrm{VHL}^{-/-}$ccRCC primary cultures and 786-O tumor cell lines have been addressed. Propranolol and ICI-118,551 activated apoptosis inhibited gene and protein expression of HIF-2 $\alpha$, CAIX, and VEGF, and impaired partially the nuclear internalization of HIF-2 $\alpha$ and NFkB/p65. Moreover, propranolol and ICI-118,551 reduced tumor growth on two in vivo xenografts. Finally, ccRCC patients receiving propranolol as off-label treatment have shown a positive therapeutic response for two years on average. In summary, propranolol and ICI-118,551 have shown antitumor benefits in VHL-derived ccRCC, and since ccRCCs comprise $63 \%$ of the total RCCs, targeting ADRB2 becomes a promising drug for VHL and other non-VHL tumors.
\end{abstract}

Keywords: $\beta$-adrenergic receptor antagonist; ICI-118,551; propranolol; HIF; ccRCC; VHL; anticarcinogenic 


\section{Introduction}

Renal cell carcinoma (RCC) ranks as the seventh most common cancer worldwide [1]. The most common histological subtype (63\%) is the clear cell renal cell carcinoma (ccRCC). Although in regular population they are sporadic, these tumors are inherited by Von Hippel-Lindau (VHL) patients and $60 \%$ of them may suffer from ccRCC in addition to other types of multisystemic tumors such as hemangioblastomas (HB).

VHL is a rare type of cancer disease with an estimated annual birth incidence of $1 / 36,000$ and a prevalence at $1 / 53,000$ in the general population [2-4]. VHL is an autosomal dominantly inherited genetic disorder and its clinical manifestations include multiple tumors that appear throughout the life span of the patient [5]. The course of VHL is associated with the development of multiple bilateral and multifocal tumors such as retinal and Central Nervous System HB (CNS-HB), ccRCC, pheochromocytomas, pancreatic islet tumors, endolymphatic sac tumors, renal and pancreatic cystadenomas, as well as broad ligament of the uterus and epididymal cystadenomas. Although VHL tumors are usually benign, RCC, pheochromocytoma, and neuroendocrine pancreatic are considered malignant tumors [6-8].

Kidneys of VHL patients usually feature both preneoplastic renal cysts and ccRCC [9,10]. It has been shown that the epithelial cells lining of these cysts present early loss of VHL and, consequently, chronic accumulation of the hypoxia inducible factor- $2 \alpha$ (HIF- $2 \alpha)$, the most prominent HIF in RCC. This HIF- $2 \alpha$ accumulation drives the activation of its target genes and tumor growth [11].

In the kidney, VHL is presumed as an early tumor suppressor gene where genetic and epigenetic events (either by mutation, loss of heterozygosity or hypermethylation of the promoter) are required for tumorigenesis and it has been documented in up to $80 \%$ of the sporadic ccRCC [12]. A recent comparison of genomic profiles revealed that VHL-associated tumors showed similar copy number changes as sporadic ccRCC [13]. Since VHL lacks an effective treatment, new drugs able to prevent repeated surgeries and to delay tumor development, including ccRCC, are in demand. Most of the systemic therapies for VHL-tumors target tyrosine kinase receptors (TKI) or proangiogenic agents, but the trials for VHL have shown limited responses (Table 1) [14,15].

To isolate and culture primary HB-tumors derived from VHL patient surgeries [16,17] open a key opportunity to characterize VHL-derived HB cells and to test drugs with therapeutic aims, thus reducing the need of recurrent surgeries in VHL patients. In this way, we also have demonstrated the therapeutic properties of propranolol, an unspecific antagonist of $\beta-1,2$-adrenergic receptor (ADRB-1,2). Propranolol was able to reduce proliferation by triggering apoptosis and, in addition, to reduce the expression of HIF target genes such as VEGF $[16,18,19]$. 
Table 1. Compilation of the VHL interventional clinical trials registered at the EU Clinical Trials Register (EudraCT) (https://www.clinicaltrialsregister.eu) and the U.S. National Library of Medicine (NCT) (https://clinicaltrials.gov). Only interventional trials whether a therapeutic drug was tested are listed. All the trials showed here were designed as single-arm, open-label trials. Abbreviations: Status: C (Completed); R (Recruiting); O (Ongoing); T (Terminated).

\begin{tabular}{|c|c|c|c|c|c|c|c|}
\hline $\begin{array}{c}\text { Trial } \\
\text { Registration } \\
\end{array}$ & Phase & Title & Intervention & $\begin{array}{l}\text { Number of } \\
\text { Patients }\end{array}$ & Status Start Date & Outcome & Link to Results \\
\hline NCT00052013 & 2 & $\begin{array}{c}\text { Treatment of Von Hippel-Lindau } \\
\text { (VHL)-Related Hemangioblastoma With } \\
\text { PTK787/ZK 222584 }\end{array}$ & $\begin{array}{l}\text { PTK787 } \\
\text { ZK 222584 } \\
\text { (vatalanib) }\end{array}$ & 11 & $\begin{array}{c}\mathrm{C} \\
\text { Feb } 2003\end{array}$ & $\begin{array}{l}\text { 100\% discontinued } \\
\text { (adverse events). }\end{array}$ & [21] \\
\hline NCT00056199 & 1 & $\begin{array}{l}\text { EYE001 } \\
\text { to Treat Retinal Tumors in Patients With Von } \\
\text { Hippel-Lindau Syndrome }\end{array}$ & $\begin{array}{l}\text { EYE001(anti-VEGF } \\
\text { aptamer) }\end{array}$ & 5 & $\underset{\text { Mar } 2003}{C}$ & $\begin{array}{l}80 \% \text { showed stabilization or } \\
\text { improvement of vision. }\end{array}$ & [22] \\
\hline \multirow{4}{*}{ NCT00088374 } & \multirow{4}{*}{2} & \multirow{4}{*}{$\begin{array}{l}\text { 17AAG to Treat Kidney Tumors in Von } \\
\text { Hippel-Lindau Disease }\end{array}$} & 1 DMAG & \multirow{4}{*}{9} & \multirow{4}{*}{$\begin{array}{c}\text { C } \\
\text { Jul } 2004\end{array}$} & \multirow{4}{*}{ Study did not meet accrual. } & \multirow{4}{*}{ [23] } \\
\hline & & & $18 \mathrm{FDG}$ & & & & \\
\hline & & & {$[15-\mathrm{O}] \mathrm{H} 2 \mathrm{O}$} & & & & \\
\hline & & & EPL diluent & & & & \\
\hline NCT00089765 & 1 & $\begin{array}{l}\text { Ranibizumab Injections to Treat Retinal } \\
\text { Tumors in Patients With Von } \\
\text { Hippel-Lindau Syndrome }\end{array}$ & Ranibizumab & 5 & $\begin{array}{c}\text { C } \\
\text { Aug } 2004\end{array}$ & $\begin{array}{l}\text { Not clear therapeutic effect. } \\
\text { "Minimal beneficial effects on most } \\
\text { VHL-related Retinal Capillary HB" }\end{array}$ & [24] \\
\hline NCT00330564 & 2 & $\begin{array}{l}\text { Evaluation of Sunitinib Malate in Patients } \\
\text { With Von Hippel-Lindau Syndrome (VHL) } \\
\text { Who Have VHL Lesions to Follow }\end{array}$ & $\begin{array}{l}\text { SU011248 } \\
\text { (Sunitinib) }\end{array}$ & 15 & $\begin{array}{c}\mathrm{T} \\
\text { May } 2006\end{array}$ & $\begin{array}{l}\text { Early termination due to slow } \\
\text { accrual. } 33 \% \text { showed partial response } \\
\text { in RCC but not in HB. }\end{array}$ & {$[25,26]$} \\
\hline NCT00470977 & $1 / 2$ & $\begin{array}{l}\text { Treatment of Exudative and Vasogenic } \\
\text { Chorioretinal Diseases Including Variants of } \\
\text { AMD and Other CNV Related Maculopathy }\end{array}$ & $\begin{array}{l}\text { Ranibizumab } \\
\text { injection } \\
(0.5 \mathrm{mg})\end{array}$ & 18 & $\begin{array}{c}\text { C } \\
\text { May } 2007\end{array}$ & - & - \\
\hline $\begin{array}{c}\text { EudraCT } \\
2007-002132-29\end{array}$ & 2 & $\begin{array}{l}\text { A Phase II Trial of Sorafenib (a tyrosine kinase } \\
\text { inhibitor) given orally twice daily in renal } \\
\text { cancer patients with vHL syndrome }\end{array}$ & Sorafenib & 25 & $\begin{array}{c}\mathrm{T} \\
\operatorname{Jan} 2008\end{array}$ & - & - \\
\hline NCT00566995 & 2 & $\begin{array}{l}\text { Phase II Study of Vandetanib in Individuals } \\
\text { With Kidney Cancer }\end{array}$ & $\begin{array}{l}\text { ZACTIMA } \\
\text { (Vandetanib) } \\
\text { (ZD6474) }\end{array}$ & 37 & $\begin{array}{c}\text { C } \\
\text { Feb } 2008\end{array}$ & $\begin{array}{l}80 \% \text { completed the study. None of } \\
\text { them showed a complete response } \\
\text { and } 8 \% \text { showed a partial response. }\end{array}$ & [27] \\
\hline NCT00673816 & $1 / 2$ & $\begin{array}{l}\text { Sunitinib Malate to Treat Advanced Eye } \\
\text { Disease in Patients With Von } \\
\text { Hippel-Lindau Syndrome }\end{array}$ & $\begin{array}{l}\text { Sunitinib } \\
\text { Malate }\end{array}$ & 2 & $\begin{array}{c}\mathrm{T} \\
\text { May } 2008\end{array}$ & $\begin{array}{l}\text { Study did not meet accrual plus } \\
\text { adverse events. }\end{array}$ & {$[28,29]$} \\
\hline NCT01015300 & 1 & $\begin{array}{l}\text { Bevacizumab (Avastin) in } \\
\text { Unresectable/Recurrent Hemangioblastoma } \\
\text { From VonHippel-Lindau Disease }\end{array}$ & Avastin & 1 & $\begin{array}{c}\mathrm{T} \\
\operatorname{Dec} 2009\end{array}$ & Study did not meet accrual. & - \\
\hline $\begin{array}{l}\text { NCT01168440 } \\
\text { EudraCT } \\
\text { 2009-013052-76 }\end{array}$ & 2 & $\begin{array}{l}\text { A single-arm, phase II study of SU11248 } \\
\text { (sunitinib) in patients with von Hippel-Lindau } \\
\text { (VHL) disease }\end{array}$ & Sunitinib & 5 & $\begin{array}{l}\text { C } \\
\text { Feb } 2010\end{array}$ & $\begin{array}{l}\text { Disease progression }(20 \%) \text {, } \\
\text { unacceptable toxicity }(60 \%) \text {, and lack } \\
\text { of clinical improvement. after } \\
7 \text { cycles }\end{array}$ & [30] \\
\hline
\end{tabular}


Table 1. Cont.

\begin{tabular}{|c|c|c|c|c|c|c|c|}
\hline $\begin{array}{c}\text { Trial } \\
\text { Registration } \\
\end{array}$ & Phase & Title & Intervention & $\begin{array}{c}\text { Number of } \\
\text { Patients }\end{array}$ & Status Start Date & Outcome & Link to Results \\
\hline $\begin{array}{c}\text { EudraCT } \\
2005-004502-82\end{array}$ & 2 & $\begin{array}{l}\text { A Phase II Study of Neoadjuvant Sunitinib in } \\
\text { Metastatic Renal Cell Carcinoma }\end{array}$ & Sunitinib & 16 & $\begin{array}{c}\mathrm{T} \\
\text { Oct } 2010 \\
\end{array}$ & $\begin{array}{c}\text { Study did not meet accrual. } 58 \% \\
\text { showed complete or partial response. }\end{array}$ & {$[31]$} \\
\hline NCT01436227 & 2 & $\begin{array}{l}\text { Pazopanib in Von Hippel-Lindau } \\
\text { (VHL) Syndrome }\end{array}$ & Pazopanib & 32 & $\begin{array}{c}\mathrm{O} \\
\text { Jan } 2012\end{array}$ & $\begin{array}{l}80 \% \text { discontinued (progressive } \\
\text { disease, loss of quality of life, or } \\
\text { intolerance). } 42 \% \text { showed partial } \\
\text { response and } 55 \% \text { a complete or } \\
\text { partial response in ccRCC. }\end{array}$ & [15] \\
\hline NCT01266070 & 2 & $\begin{array}{l}\text { TKI } 258 \text { in Von Hippel-Lindau } \\
\text { Syndrome (VHL) }\end{array}$ & Dovitinib & 6 & $\begin{array}{c}\mathrm{T} \\
\text { Nov } 2012 \\
\end{array}$ & $\begin{array}{l}33 \% \text { discontinued plus the trial met } \\
\text { toxicity stopping rule. }\end{array}$ & {$[32,33]$} \\
\hline $\begin{array}{c}\text { EudraCT } \\
\text { 2014-003671-30 }\end{array}$ & 3 & $\begin{array}{l}\text { Therapeutic effect of propranolol in a series of } \\
\text { patients with von Hippel-Lindau disease and } \\
\text { retinal hemangioblastomas in short, medium } \\
\text { and long term treatment. }\end{array}$ & Propranolol & 7 & $\begin{array}{c}\text { C } \\
\text { Oct } 2014\end{array}$ & $\begin{array}{l}28 \% \text { showed partial response and } \\
72 \% \text { a stable disease. No serious } \\
\text { adverse effects were recorded. }\end{array}$ & {$[19,20]$} \\
\hline NCT02108002 & 1 & $\begin{array}{l}\text { Effect of Vorinostat on Nervous System } \\
\text { Hemangioblastomas in Von Hippel-Lindau } \\
\text { Disease (Missense Mutation Only) }\end{array}$ & Vorinostat & 7 & $\begin{array}{c}\text { C } \\
\text { Apr } 2014\end{array}$ & - & - \\
\hline NCT02859441 & $1 / 2$ & $\begin{array}{l}\text { A Phase I/II Trial for Intravitreous Treatment of } \\
\text { Severe Ocular Von Hippel-Lindau Disease } \\
\text { Using a Combination of the PDGF Antagonist } \\
\text { E10030 and the VEGF } \\
\text { Antagonist Ranibizumab }\end{array}$ & $\begin{array}{l}\text { Ranibizumab } \\
\text { \& E10030 } \\
\text { (anti-PDGF } \\
\text { pegylated } \\
\text { aptamer) }\end{array}$ & 3 & $\begin{array}{c}\text { C } \\
\text { Aug } 2016\end{array}$ & - & - \\
\hline NCT03108066 & 2 & $\begin{array}{l}\text { PT2385 for the Treatment of Von } \\
\text { Hippel-Lindau Disease-Associated Clear Cell } \\
\text { Renal Cell Carcinoma }\end{array}$ & $\begin{array}{l}\text { PT2385 } \\
\text { Tablets (HIF-2 } \alpha \\
\text { inhibitor) }\end{array}$ & 4 & $\begin{array}{c}\mathrm{O} \\
\text { May } 2017\end{array}$ & - & - \\
\hline NCT03401788 & 2 & $\begin{array}{l}\text { A Phase } 2 \text { Study of PT2977 for the Treatment } \\
\text { of Von Hippel Lindau Disease-Associated } \\
\text { Renal Cell Carcinoma }\end{array}$ & $\begin{array}{c}\text { PT2977 } \\
\text { (HIF-2 } \alpha \text { inhibitor) }\end{array}$ & 61 & $\begin{array}{c}\text { C } \\
\text { Mar } 2018\end{array}$ & $27.9 \%$ showed partial response. & {$[34]$} \\
\hline
\end{tabular}


Furthermore, a phase III clinical trial (EudraCT: 2014-003671-30) was conducted to address the safety and effectiveness of propranolol in VHL patients with retinal HB (Table 1). Briefly, the number and size of retinal HB remained stable in all patients and VEGF and miR210 plasma levels were reduced to normal levels after propranolol treatment $[19,20]$. Nevertheless, hypotension and bradycardia were the main side effects registered, both as consequence of propranolol's main attribute-reducing blood pressure. Thus, it proves to be inappropriate for patients with normal or low blood pressure. These side effects of propranolol are driven exclusively by its ADRB-1 blockade, and therefore could be avoided, while keeping the previously mentioned benefits, by using a high specific ADRB-2 antagonist.

Among the $\beta$-blockers, one selective antagonist of the ADRB-2, the erythro-D,L-1 (methylinden-4-xyloxy)-3-isopropylaminobutan-2-ol, known as ICI-118,551 (ICI), stands out. Cuesta et al. recently reported the similarities of ICI and propranolol effects on VHL patient-derived $\mathrm{HB}$ cultures, such as a specific decrease of cell viability and apoptosis triggering in CNS-HB primary tumors [18]. Based on these data, we wondered whether $\beta$-antagonists would also show its therapeutic properties on a more malignant VHL-related carcinoma, such as the ccRCC. Therefore, in line with the previous results obtained on $\mathrm{HB}$, we isolated, established, and tested both $\beta$-antagonists on RCC primary tumors from VHL patients.

Since VHL-derived ccRCC grow under HIF transcriptional stimulation, as it is the case in HB, development of primary tumors from ccRCC derived from VHL-RCC surgeries was the first aim of the present work. In addition, cell viability, apoptosis, gene expression, with emphasis in HIF-2 $\alpha$ and its targets, and the in vitro and in vivo carcinoma cell responses to ADRB antagonists, including propranolol and ICI, were evaluated, demonstrating their positive effects. These results were further reinforced with clinical data collected from VHL-ccRCC patients under propranolol treatment for more than 15 months, who showed a better outcome during propranolol treatment.

\section{Results}

\subsection{Isolation and Cultivation of Primary ccRCC Tumor Cultures from Surgical Specimens}

Up to 15 different VHL-ccRCC primary cultures have been collected, isolated, and cultivated, and an average of three different ccRCC samples were used for the in vitro assays (ccRCC samples were identified with an internal numerical code, indicating individual patient tissue isolates). Among them and due to cell availability, 5 different ccRCC samples were assayed for the present manuscript. Representative images from first passages of primary VHL-ccRCC tumor cultures are shown in Figure 1A. Until the first confluence, cells exhibited epithelioid morphology, growing in groups or "foci" with an elongated or rounded shape before becoming confluent cells. The already described lipid accumulation, typical for ccRCC, could be observed during the first passages of the primary culture.

The nature of the primary cultures as ccRCC is based on clinical and morphological data. First, they are derived from tumoral surgery surplus of patients previously diagnosed as suffering from VHL. Second, the preliminary clinical pathology analysis determined the kind of RCC, being classified as ccRCCs. Moreover, they have been extensively described in literature, becoming a good model to recapitulate the cCRCC [35]. In addition, the expression of the carbonic anhydrase IX (CAIX), a well-known marker for ccRCC, was tested by immunofluorescence and qPCR proving the ccRCCs identity of our primary cultures (Figure 2D and Figure S1, respectively).

VHL-derived ccRCC primary tumors are a model that may represent the ccRCC biology and which could prospectively be used for in vitro functional analyses [35]. Thus, we used these primary tumors to assess the putative therapeutic properties of $\beta$-antagonists, the non-specific propranolol and the $\beta 2$-specific ICI. 
A

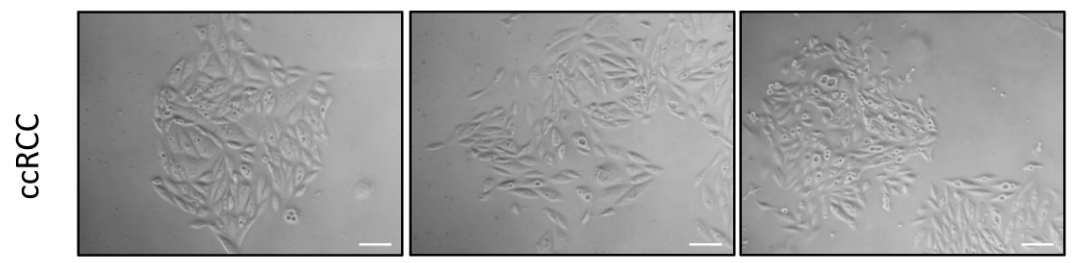

B
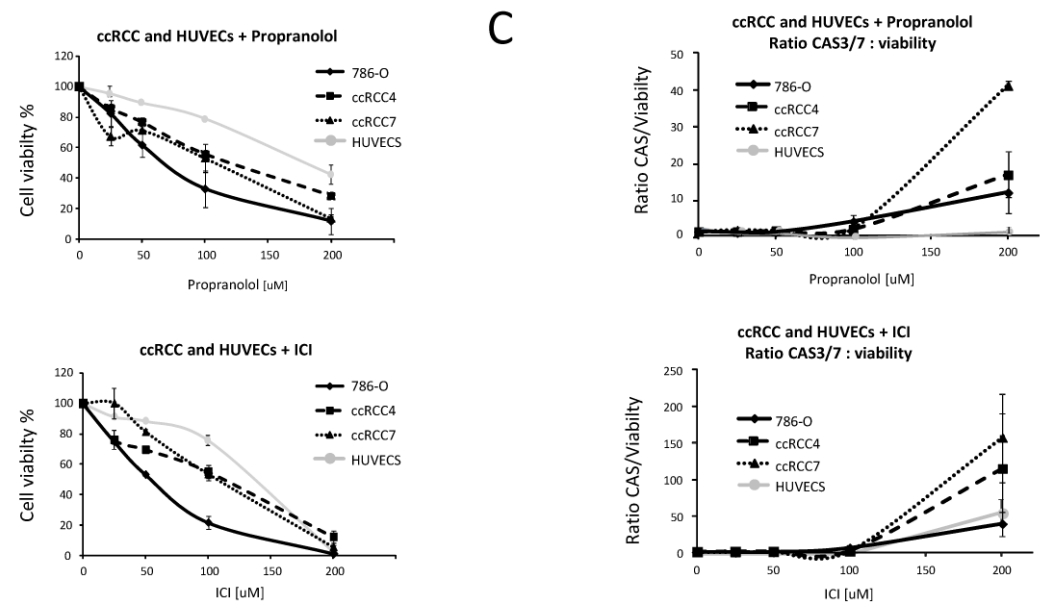

D

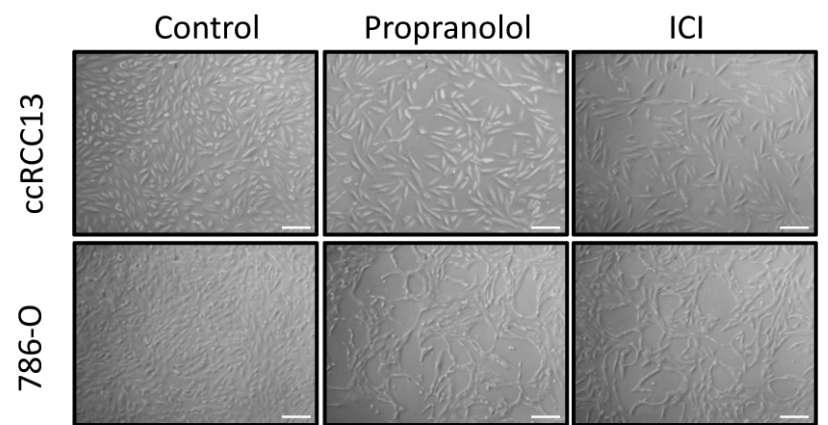

$E$

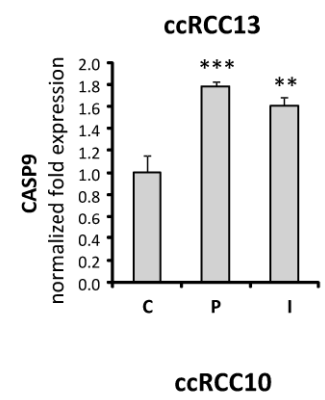

F
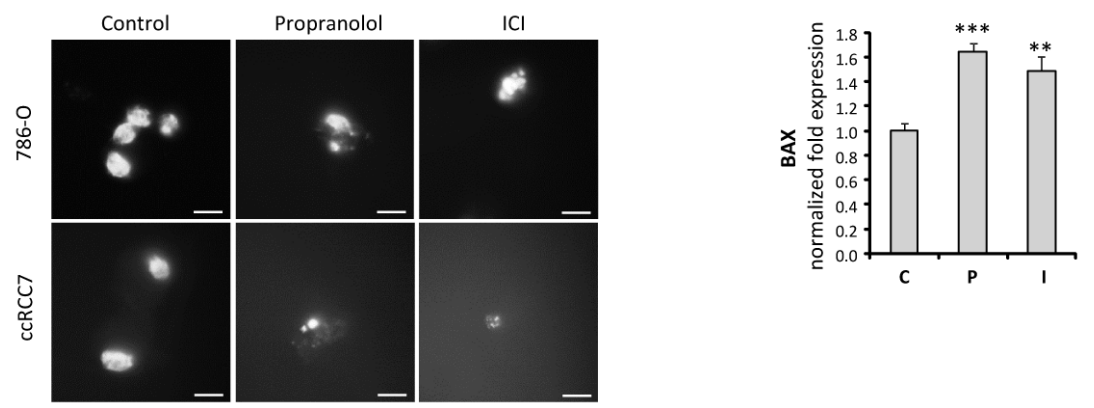

Figure 1. Effect of $\beta 2$-adrenergic receptor (ADRB) blockers on cell viability of $\mathrm{VHL}^{-/-}$and $\mathrm{VHL}^{+/+}$ cells. (A). Representative images of a primary clear cell renal cell carcinoma (ccRCC) tumor culture derived from a VHL patient. (B,C). Effect of $\beta 1$ and $\beta 2$-adrenergic receptor blockage in cell viability and Caspases 3/7 activation after propranolol and ICI-118,551 (ICI) incubation on $\mathrm{VHL}^{-/}$ccRCC cells such as 786-O, ccRCC4, and ccRCC7 and on the $\mathrm{VHL}^{+/+}$endothelial primary cells HUVECs. Cultures were treated with increasing doses [0-200 $\mu \mathrm{M}]$ propranolol or ICI for $72 \mathrm{~h}$. (D). Representative images of ccRCC13 and 786-O cultures treated with $100 \mu \mathrm{M}$ propranolol or ICI for $72 \mathrm{~h}$. (E). mRNA quantification of the apoptotic genes CASP9 and BAX on ccRCC primary tumors treated with $100 \mu \mathrm{M}$ propranolol or ICI for $72 \mathrm{~h}$. (F). Propranolol and ICI cause chromatin condensation induced by cellular apoptosis. All data are based on 3 independent experiments. Scale bars represent $100 \mu \mathrm{m}(\mathbf{A}, \mathbf{D})$ and $50 \mu \mathrm{m}(\mathbf{F})$. Abbreviations: C, P, and I for control, propranolol, and ICI, respectively. Error bars denote \pm SEM. Student's $t$-test: ${ }^{*} p<0.05 ;{ }^{* *} p<0.01 ;{ }^{* * *} p<0.001$. 
A

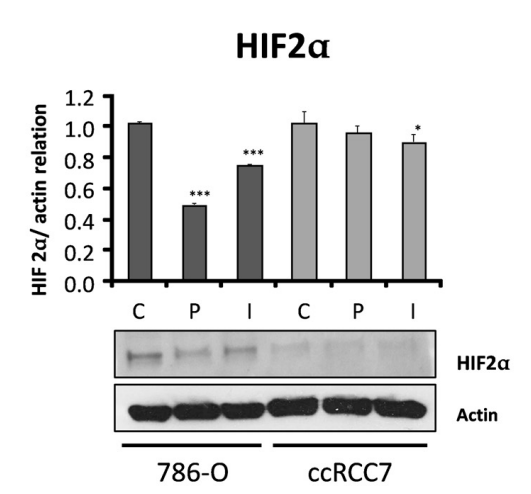

B

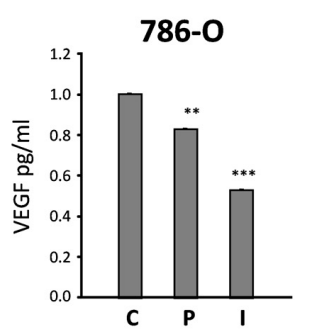

C

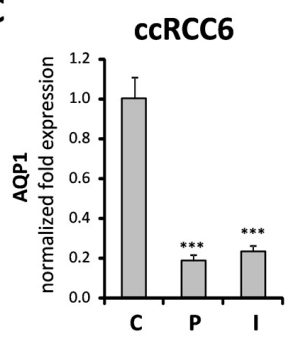

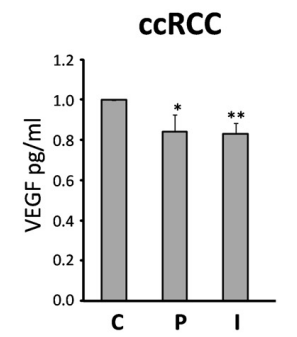

ccRCC13

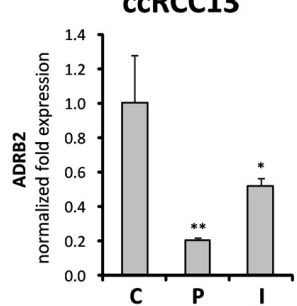

D
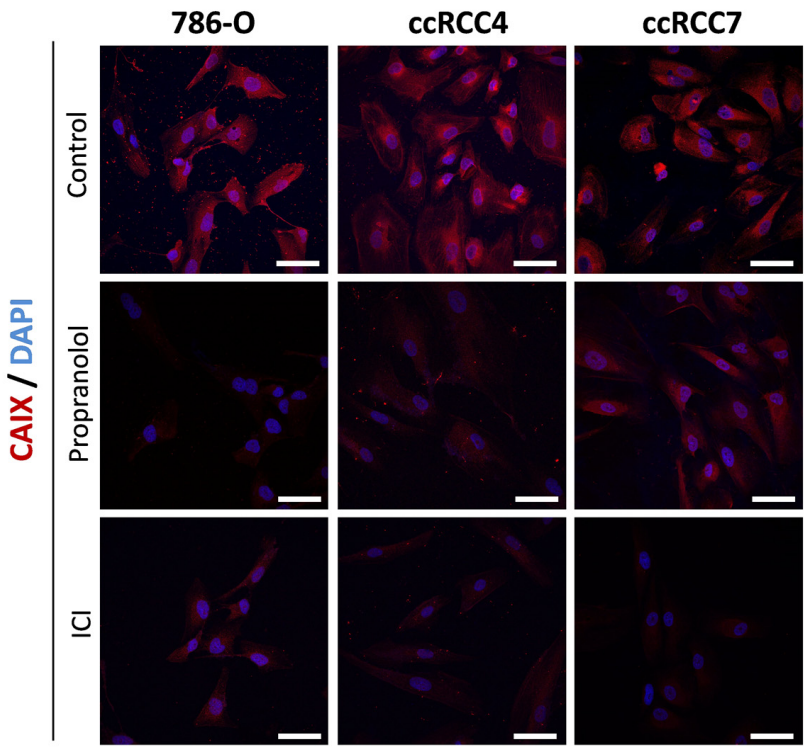

CCRCC13
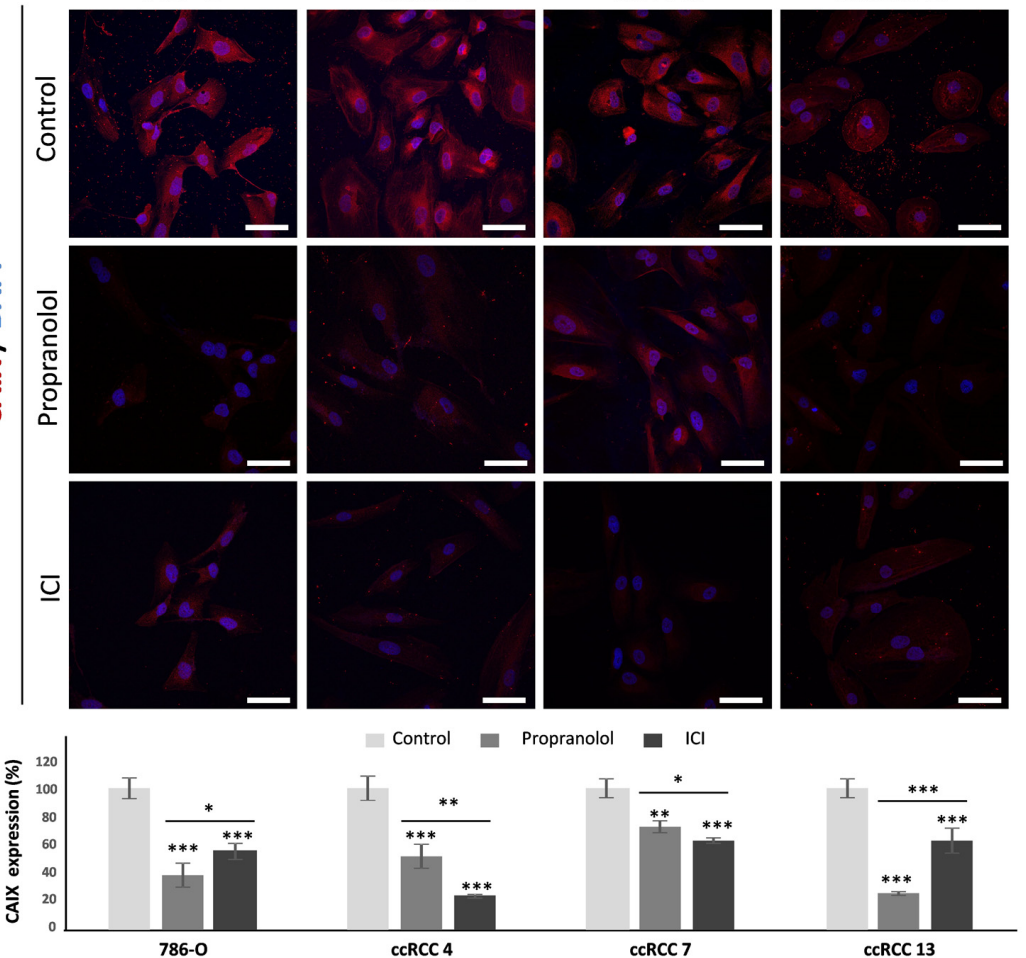

a Control — Propranolol a ICI
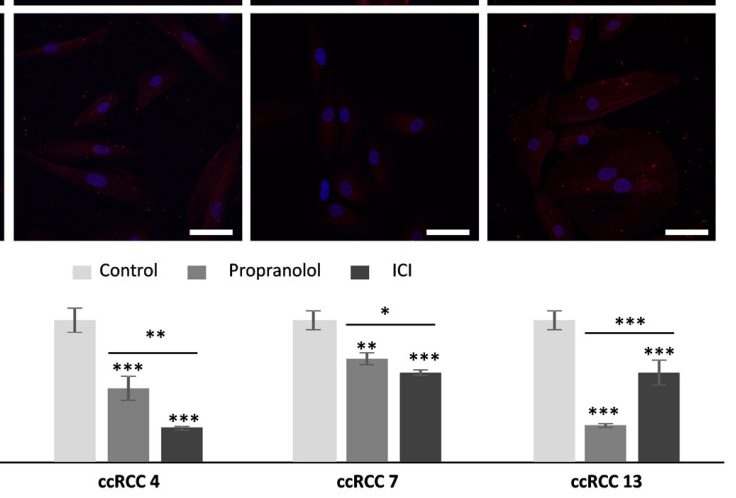

Figure 2. Effects of ADRB antagonists on VHL gene targets. (A). HIF-2 $\alpha$ protein expression on $786-\mathrm{O}$ and ccRCC cells after treatment with $100 \mu \mathrm{M}$ propranolol or ICI for $72 \mathrm{~h}$. Protein cell lysates were analyzed by Western blot, actin was used as loading control and for normalized quantification (representative assay). (B). Secreted VEGF levels in supernatants of cells treated with $100 \mu \mathrm{M}$ propranolol or ICI for $48 \mathrm{~h}$ were measured by ELISA. VEGF data from ccRCC represents the average of three different tumor samples. (C). mRNA quantification of the HIF target genes $A Q P-1$ on ccRCC primary tumors treated with $100 \mu \mathrm{M}$ propranolol or ICI for $72 \mathrm{~h}$. (D). Immunofluorescence detection and confocal microscopy representative images from 786-O and ccRCC cultures treated with $100 \mu \mathrm{M}$ PBS, propranolol, or ICI for $48 \mathrm{~h}$. Up, mouse anti-human CAIX antibody stains (red) and DAPI nuclear staining (blue) merged images. Down, relative quantification of CAIX expression on each cell line after treatment. For quantification procedures, $20-50$ cells were measured for CAIX intensity from 3 replicates per condition. Scale bars represent $50 \mu \mathrm{m}$. All data are based on 3 independent experiments. Abbreviations: $C, P$, and I for control, propranolol, and ICI, respectively. Error bars denote \pm SEM. Student's $t$-test: ${ }^{*} p<0.05 ; * * p<0.01 ;{ }^{* * *} p<0.001$. 


\subsection{Cell Viability of ccRCC Primary Tumors and RCC 786-O Cell Line Is Impaired after ADRB Blockers Treatment by Triggering Apoptosis}

Figure 1B shows the viability in two different ccRCC primary tumors (ccRCC 4 and 7), the $\mathrm{VHL}^{-/-}$ human RCC cell line 786-O, and the $V H L^{+/+}$Human Umbilical Vein Endothelial Cell (HUVECs) after treatment with different doses of propranolol or ICI for $72 \mathrm{~h}$. Propranolol and ICI decrease ccRCC cell viability in a dose-dependent manner, reaching IC50 levels around $100 \mu \mathrm{M}$ for both $\beta$-blockers. $786-\mathrm{O}$ cells are proved to be more sensitive to $\beta$-antagonists, reaching less than $60 \%$ of viability at $50 \mu \mathrm{M}$ and $40 \%$ or less at $100 \mu \mathrm{M}$ propranolol or ICI. In addition, the ratio shown in Figure $1 \mathrm{C}$ indicates the number of live cells in which the apoptotic mechanisms, caspases $3 / 7$, are activated. HUVECs, corresponding to primary endothelial VHL positive cells was used as control of healthy vasculature.

In addition, to show specificity of the ADRB blockers on tumoral cells vs. non-cancerous cells, the LD50 calculations of the ccRCC cells were done as well as previously published data from HUVECs, a non-cancerous endothelial primary culture [18], and the human renal cancer cell line 786-O. These results demonstrate that LD50 for 786-O cells ranges around $67 \mu \mathrm{M}$ for propranolol and $55 \mu \mathrm{M}$ for ICI, LD50 for primary ccRCC cultures range from 110 to $120 \mu \mathrm{M}$ for both ADRB antagonists, and LD50 for HUVECs ranges around $175 \mu \mathrm{M}$ for propranolol and $138 \mu \mathrm{M}$ for ICI, (Table S1). Therefore, there is a notable difference between the LD50 of ccRCC tumor cells as compared to healthy ones, in vitro, opening an important therapeutic window of opportunity.

The effect on cell death becomes more clearly visible when primary tumors are cultivated in vitro in the absence or presence of $\beta$-blockers for $72 \mathrm{~h}$. Figure 1D shows a confluent cell monolayer in the absence of any treatment, and discontinuities of this layer become apparent after treatment with $100 \mu \mathrm{M}$ propranolol or ICI. Moreover, the cellular morphology varies, becoming elongated and showing cell debris as indicative of apoptosis. Apoptosis, as origin of the decreased viability after ADRB blockers propranolol and ICI treatment on VHL-derived primary tumors, has been previously reported in literature $[16,18,19]$.

To confirm the apoptotic cell death induction in our primary VHL-ccRCC isolates, we assessed the expression of two pro-apoptotic genes, BAX and CASP9, by quantitative PCR. Figure 1E shows that the expression of $C A S P 9$ was significantly upregulated after $72 \mathrm{~h}$ of treatment with $100 \mu \mathrm{M}$ of either propranolol or ICI ( $p=0.00062$ and $p=0.0020$, respectively). BAX expression was significantly upregulated too (propranolol; $p=0.00013$ and ICI; $p=0.0017$ ).

Figure $1 \mathrm{~F}$ reinforces the previous results shown in this figure, where the condensation and fragmentation of nuclei can be observed due to the apoptosis process in ccRCC cultures after $\beta$-blocker treatment. Taken together, propranolol and ICI seem to act in a dose-dependent manner, triggering apoptosis on both primary tumors and RCC cell lines.

Altogether, the data displayed on Figure 1C-F support the idea of apoptosis being the mechanism causing the decrease in primary ccRCC tumor cell viability after $\beta$-antagonist treatment in ccRCC.

\subsection{Propranolol and ICI-118,551 Decrease HIF, VEGF, and CAIX Expression}

Due to the lack of functional pVHL in VHL-ccRCC primary tumor cells and in 786-O cells, HIF proteins are not targeted for proteasomal degradation and can accumulate in the cell [2-5]. As shown in Figure 2A, the levels of protein HIF- $2 \alpha$ significantly decreased after $72 \mathrm{~h}$ of $100 \mu \mathrm{M}$ of either propranolol or ICI treatment. 786-O cells are more sensitive to $\beta$-blockers than ccRCC primary tumors, with propranolol being more effective in the cell line and ICI on the ccRCC primary tumors.

The amount of VEGF, a direct HIF target, secreted by 3 different primary cultures of VHL-ccRCCs and 786-O cells was significantly reduced after a 48-h treatment with $100 \mu \mathrm{M}$ propranolol or ICI. The amount of VEGF secreted into the culture medium was measured by ELISA and compared to untreated cells. As shown in Figure 2B, propranolol $(p=0.0059)$ and ICI $(p=0.0005)$ significantly decreased the amount of VEGF secreted by 786-O cells. This was also observed in ccRCC with both propranolol $(p=0.014)$ and ICI $(p=0.0028)$, at variance with the results published by Shepard et al. [36], in which VEGF levels remained unchanged after $200 \mu \mathrm{M}$ of propranolol treatment. Moreover, we also 
found a significant reduction of almost $20 \%$ in VEGF expression compared to the control, in three independent primary VHL-ccRCCs cultures treated with $100 \mu \mathrm{M}$ of either propranolol or ICI. Figure 2C represents the mean of 3 different assays done with primary tumors obtained from 3 non-related VHL-ccRCCs. Additionally, AQUAPORIN-1 (AQP-1), another HIF target highly expressed in different tumors [37-39], was significantly decreased after treatment with propranolol or ICI ( $p=0.00012$ and $p=0.00015$, respectively). Interestingly and in agreement with the result observed in CNS-HBs [18], $A D R B-2$ expression was also significantly downregulated by the ADRB antagonists, as shown in Figure 2C ( $p=0.003$ for propranolol and $p=0.021$ for ICI).

Lastly, the biomarker for RCC CAIX is a HIF target. Knowing that HIF levels were reduced after ADRB antagonist treatment, we wondered about CAIX expression levels. As shown in Figure 2D, the cell line 786-O and three different VHL-ccRCCs primary cultures were treated either with PBS, propranolol, or ICI. As observed, the blockage of ADBR-2 significantly decreased CAIX expression in all the cells tested. Interestingly, HIF-2 $\alpha$ and CAIX levels were similarly reduced in 786-O and ccRCC7 cells (Figure 2A,D). Altogether, the reduction of HIF expression by propranolol and ICI impairs the HIF signaling pathway in both, 786-O cell line and primary tumors, suggesting potent antitumor properties.

Figure 2 shows that the intensity of the cell response to the treatment with propranolol and ICI, is variable, and it reflects the heterogeneity of primary cultures derived from tumors of different VHL patients and harboring distinct VHL mutations.

\subsection{HIF-2 $\alpha$ Cell Distribution Is Altered by the ADRB Antagonists}

Lack of VHL protein prevents HIF degradation, allowing its accumulation even under normoxic conditions (pseudo-hypoxic state), therefore triggering their downstream signaling pathways. We have observed that propranolol and ICI reduce but do not abolish HIF protein levels and impair the expression of HIF-target genes like VEGF and $A Q P-1$. Thus, we wondered whether the ADRB antagonists propranolol and ICI could play a role in the cellular distribution of HIF. To address this question, the RCC cell line 786-O, a standard model for $\mathrm{VHL}^{-/-}$, was used to assess HIF-2 $\alpha$ distribution in the cellular compartments (nucleus vs. cytoplasm), before and after the treatment with $\beta$-blockers, by an immunofluorescence confocal microscopy assay.

Quantitative analysis of HIF- $2 \alpha$ distribution showed that it was more abundant in the cytoplasm $(70 \%)$ than in the nuclei (30\%) of untreated 786-O cells (Figure 3). When cells were treated with either propranolol or ICI, nuclear HIF- $2 \alpha$ protein was significantly reduced to $22.7 \%$ and $23.5 \%(p=0.0052$ and $p=0.0195)$, respectively. No significant differences exist between propranolol or ICI treated cells on HIF- $2 \alpha$ nuclear localization $(p=0.32970)$.

In summary, these data demonstrate that the $\beta 2$-adrenergic antagonists propranolol and ICI, do not only decrease HIF expression but also change HIF subcellular localization. Decreased HIF localization in the nuclear compartment after $\beta 2$ adrenergic antagonists treatment (Figure 3) may at least partially explain the reduced levels of AQP-1 and VEGF mRNA shown in Figure 2B,C. Similar results have been obtained by our group in VHL CNS-HBs and HUVECs under hypoxic conditions $[16,19]$ and by the group of Zhang et al. in 2016 with vorinostat, a histone deacetylase inhibitor [40]. 


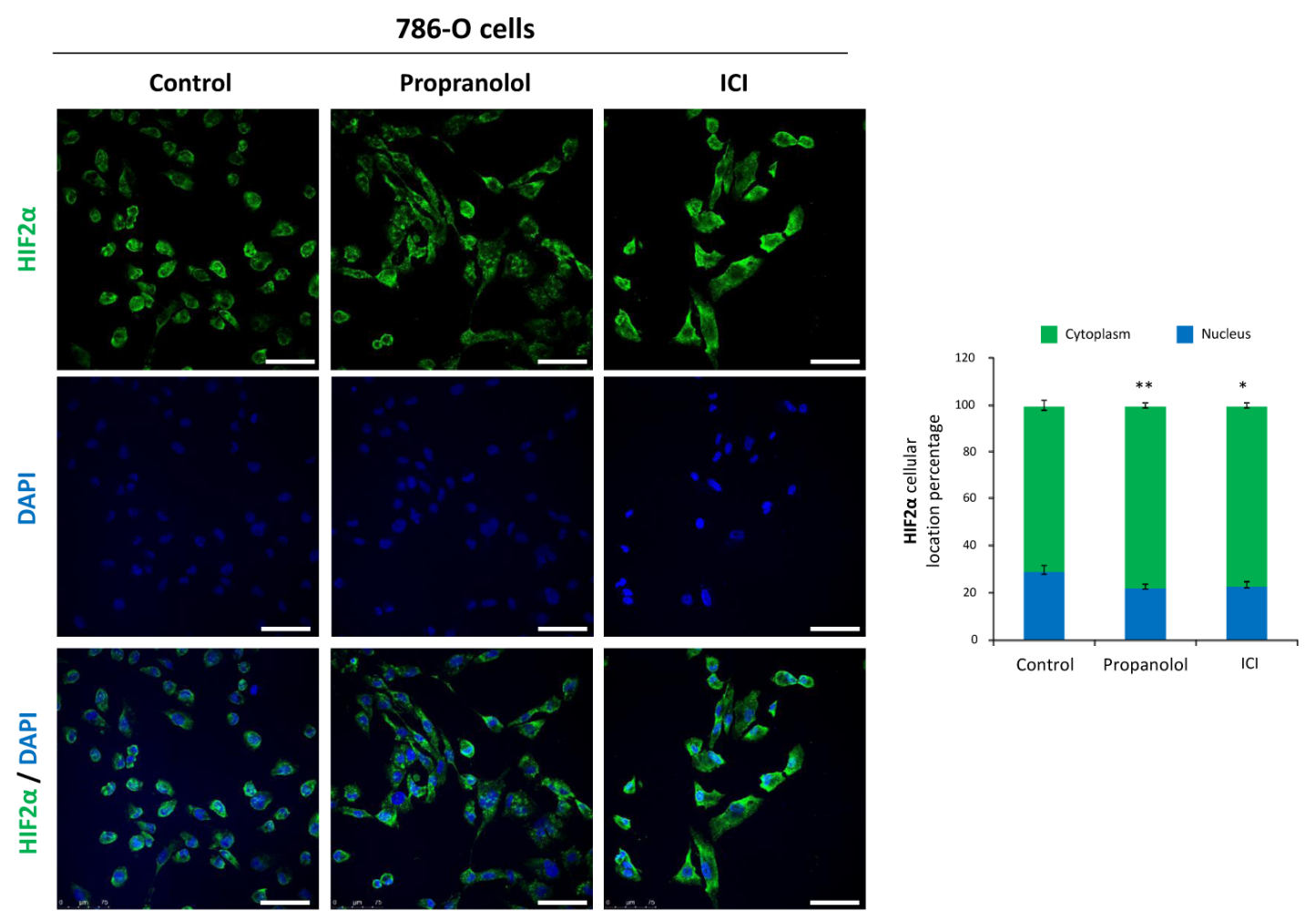

Figure 3. Effect of $\beta 2$-adrenergic receptor blockage on HIF- $2 \alpha$ subcellular distribution. Left, immunofluorescence detection and confocal microscopy representative images from 786-O cells treated with $100 \mu \mathrm{M}$ propranolol or ICI for $72 \mathrm{~h}$. Mouse anti-human HIF-2 $\alpha$ antibody stains (green), DAPI nuclear staining (blue) and merged are shown. Right, relative quantification of HIF- $2 \alpha$ nuclei or cytoplasmic distribution. For quantification procedures, 12 different optic fields were taken from 4 replicates per condition. Scale bars represent $50 \mu \mathrm{m}$. Error bars denote \pm SEM. Student's $t$-test: ${ }^{*} p<0.05 ;{ }^{* *} p<0.01 ;{ }^{* * *} p<0.001$.

\subsection{NFאB-p65 Pathway Is Targeted by the ADRB Blockers}

$\mathrm{NF} \kappa \mathrm{B}$ pathway is a main inflammatory pathway naturally inhibited by I $\kappa$ B. Upstream activating signals (e.g., binding of TNF- $\alpha$, IL- $1 \alpha$, LPS, CD40, or other unknown ligands to its receptor) cause

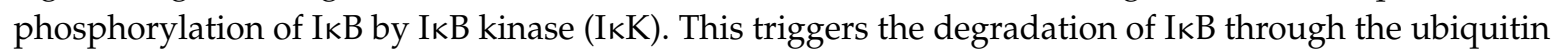
system. The free unbound NFKB protein, p65, can then translocate to the nucleus and activate transcription of target genes [41]. Malec et al. reported that 786-O cells showed a 4-fold increased $\mathrm{NF} \kappa \mathrm{B}$ activity under basal conditions, as compared to 786-O expressing VHL after a stable transfection, and they concluded that enhanced activity of the NFKB pathway was associated with the loss of $V H L$ in these cells [42]. In line with these observations, we explored the expression and translocation of p65/RelA, a main component of the NFkB pathway, in 786-O cells in basal conditions or after treatment with either propranolol or ICI. Figure $4 \mathrm{~A}$ show the immunofluorescence staining of p65 in control conditions and after the treatment with $\beta$-blockers. Moreover, histograms indicate the relative amount of p65 localized in the nucleus and in the cytoplasm. Under control conditions, p65 is highly expressed and almost evenly distributed between the nuclei and the cytoplasm $(45 \%$ and $55 \%$, respectively). However, $\beta$-antagonists significantly alter p65 nuclear localization, resulting in a $32 \%$ and $43 \%$ reduction in nuclear localization after propranolol $\left(p=9.13 \times 10^{-8}\right)$ and ICI $\left(p=6.35 \times 10^{-7}\right)$ treatment, respectively. Therefore, this result seems to indicate that NFkB signaling in 786-O cells is also decreased by $\beta$-blockers. Next, we wondered about the downstream effects of the $\beta$-antagonists in the NFKB signaling pathway. We tested three different ccRCCs primary tumors and analyzed the expression of three interleukins triggered by p65: IL-1 $\beta$, IL-6, and TNFAIP6. As shown in Figure 4B, all these NFKB targets were significantly downregulated by propranolol and ICI. 
A

$786-0$ cells

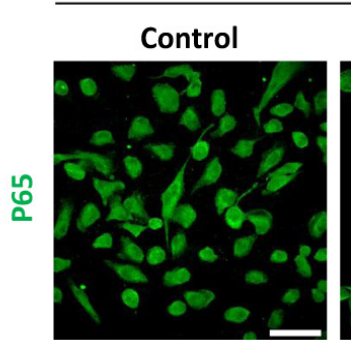

\section{Propranolol}
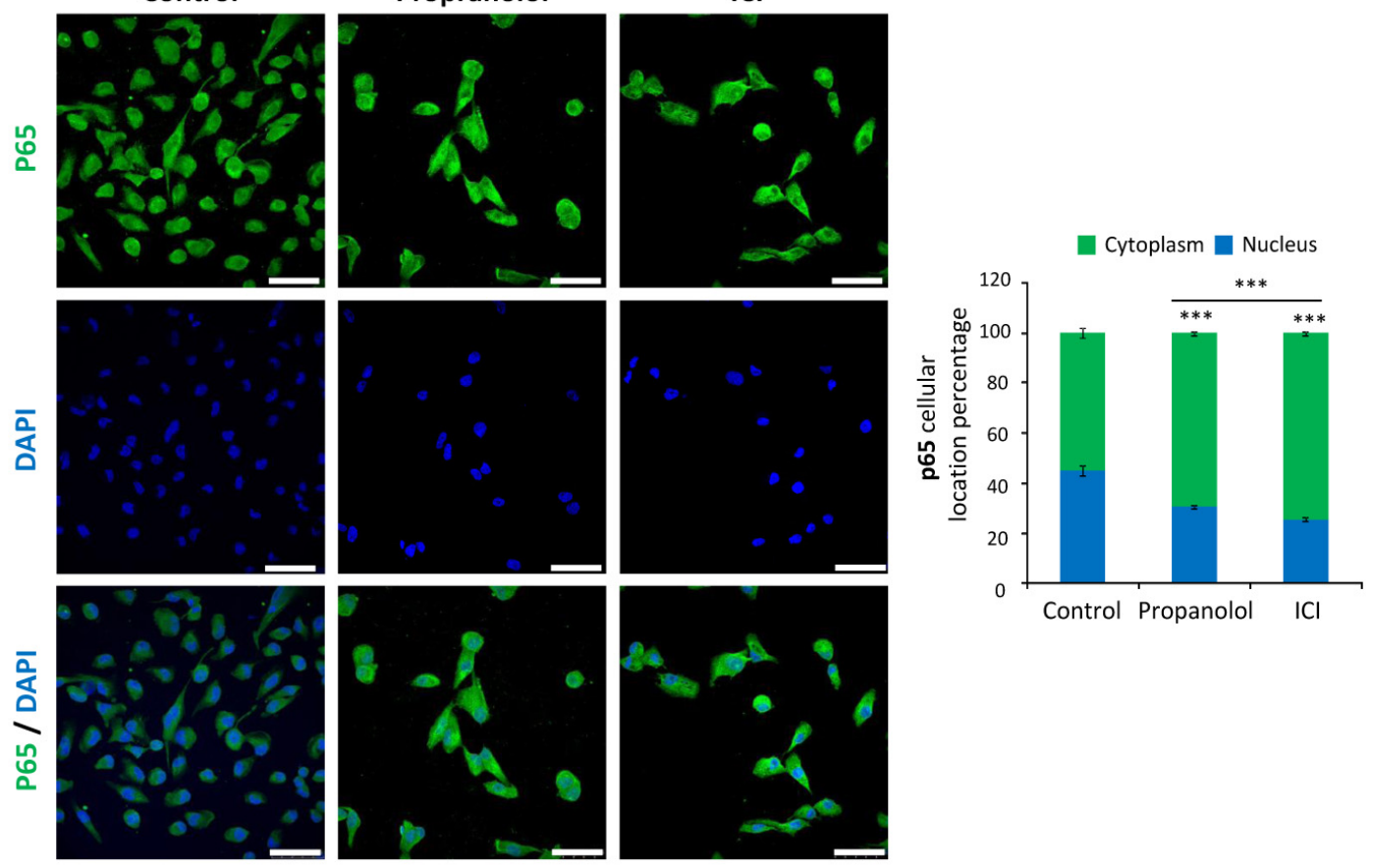

B
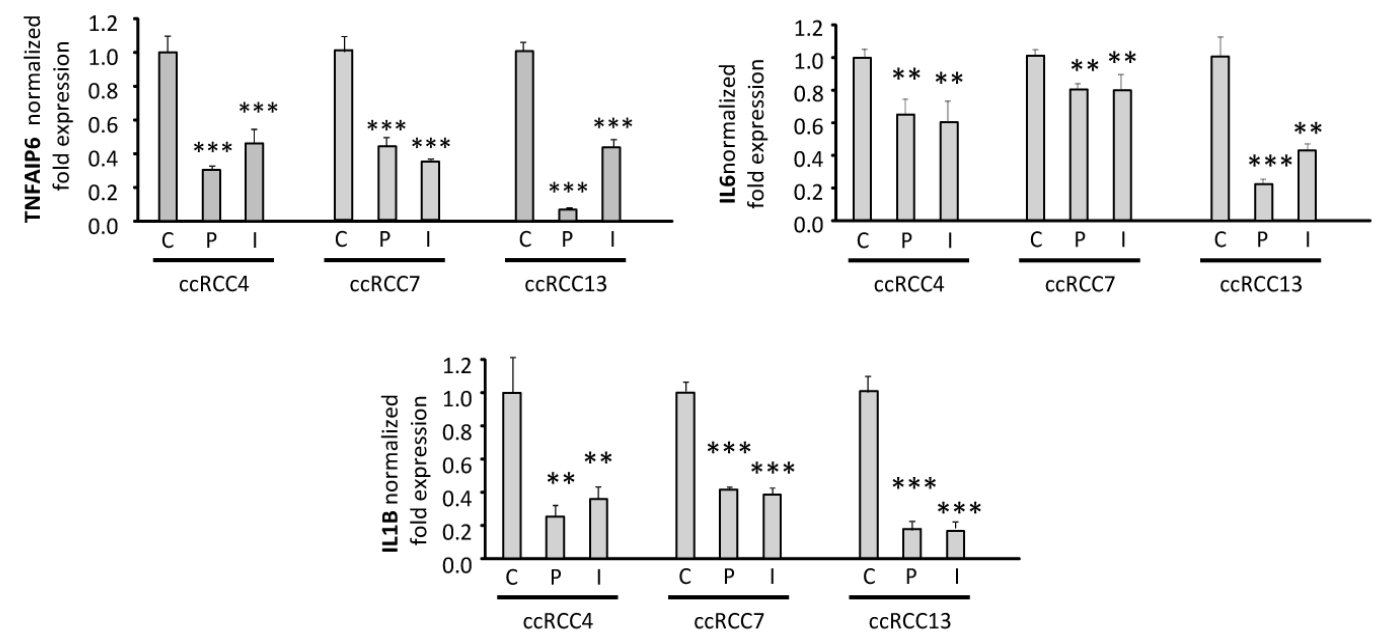

Figure 4. Effect of $\beta 2$-adrenergic receptor blockage on p65 subcellular distribution. (A). Left, immunofluorescence detection and confocal microscopy representative images from 786-O cells treated with $100 \mu \mathrm{M}$ propranolol or ICI for $72 \mathrm{~h}$. Mouse anti-human p65 antibody stains (green), DAPI nuclear staining (blue) and merged are shown. Right, relative quantification of p65 nuclei or cytoplasmic distribution. For quantification procedures, 12 different optic fields were taken from 4 replicates per condition. Scale bars represent $50 \mu \mathrm{m}$. (B). mRNA quantification of the NFKB target genes: TNFAIP6 (up-left), IL-6 (up-right), and IL-1 $\beta$ (down). mRNA expression levels were measured in different ccRCC primary tumors after treatment with $100 \mu \mathrm{M}$ propranolol or ICI for $72 \mathrm{~h}$. Abbreviations: C, P, and I for control, propranolol, and ICI, respectively. Error bars denote \pm SEM. Student's $t$-test: ${ }^{*} p<0.05$; ** $p<0.01 ;{ }^{* * *} p<0.001$. 


\subsection{ICI-118,551 and Propranolol Treatment Decreases the Growth Rate of ccRCC VHL ${ }^{-/-}$786-O Tumor} Xenograft in NSG Mice

Our previous results pointed towards a potential benefit of the $\beta$-blockers for the treatment of VHL, but a confirmation with a relevant in vivo animal model was required to support this hypothesis. To achieve this, two different approaches were developed in order to mimic two scenarios: a classic solid tumor case and a VHL case.

The first in vivo approach mimics a VHL scenario, where VHL patients are periodically evaluated and their established RCCs (and/or retinal or CNS-HBs) are imaged to calculate their volume and growth speed. Typically for VHL patients in the clinic, when renal tumors increase by $3 \mathrm{~cm}$ in diameter, partial or total nephrectomy is required. In our in vivo study, treatment with either of the drugs $(10 \mathrm{mg} / \mathrm{kg} / \mathrm{day})$ started on the day after the 786-O tumor cells were subcutaneously implanted ( $10^{6}$ cells/mouse) and continued for the first five consecutive days. As shown in Figure 5A, the treatment with propranolol or ICI for only five days was effective enough to significantly delay the tumor growth, especially in the case of propranolol ( $p=0.0131$ for propranolol and $p=0.0490$ for ICI). Particularly, propranolol-treated tumors needed about 10 days more than the vehicle group to reach $100 \mathrm{~mm}^{3}$ ( $37 \mathrm{vs}$. 27, respectively). In the vehicle-treated group, tumors needed 31 days to reach about $150 \mathrm{~mm}^{3}$, while ICI-treated tumors needed 40 days and propranolol-treated ones 46 days. Furthermore, at the end of the experiment (day 46), average tumor size in the control group was almost double of that in the propranolol cohort (323.8 vs. $162.9 \mathrm{~mm}^{3}$, respectively), and approximately $35 \%$ larger in volume than ICI-treated tumors (323.8 vs. $211.9 \mathrm{~mm}^{3}$, respectively). Moreover, no adverse effects were observed during the whole time of the in vivo study, followed up by animal behavior observation and weight evolution.

In the second study, we tried to mimic the classical in vivo cancer therapeutic intervention. For this, the ccRCC human cell line 786-O was subcutaneously implanted into NSG mice $\left(10^{6} 786-\mathrm{O}\right.$ cells/mouse) and propranolol or ICI treatment $(10 \mathrm{mg} / \mathrm{kg} /$ day $)$ was initiated when the tumor sizes averaged $100 \mathrm{~mm}^{3}$. Tumor growth kinetics are shown in Figure 5B. Already 4 days after treatment initiation, the average tumor volume from the treated groups was significantly reduced $(6.1 \%$ and $9.7 \%$ for propranolol and ICI, respectively), with the antitumor effect becoming significantly stronger in the case of ICI on day 35 after treatment initiation $(p=0.0427)$. Propranolol treatment also resulted in a significant tumor growth reduction (as shown on day 50, $p=0.0123$ ). At the end of the study, on day 58 (21 days after treatment initiation), both propranolol and ICI were able to significantly inhibit tumor growth ( $26 \%$ and $p=0.0141$ and $20 \%$ and $p=0.0131$, respectively), and were able to create a 7 -day window of tumor growth retardation (at day 50 ). We also observed a reduction in tumor weight by $8 \%$ and $24 \%$ upon propranolol and ICI treatment ( $p=0.2712$ and $p=0.0961$, respectively) (Figure 5C). Moreover, despite the daily treatment, no adverse effects were observed during the whole time of the treatment, followed up by animal behavior observation and weight evolution.

Finally, expression of HIF- $2 \alpha$ protein on tumor samples was addressed immunohistochemically. Figure 5D shows a clear reduction of HIF- $2 \alpha$ expression on ADRB blockers-treated mice, as observed in vitro (Figure 2A).

These in vivo data demonstrate the antitumor properties of propranolol and ICI and the lack of major side effects when tested in a murine model. 
A

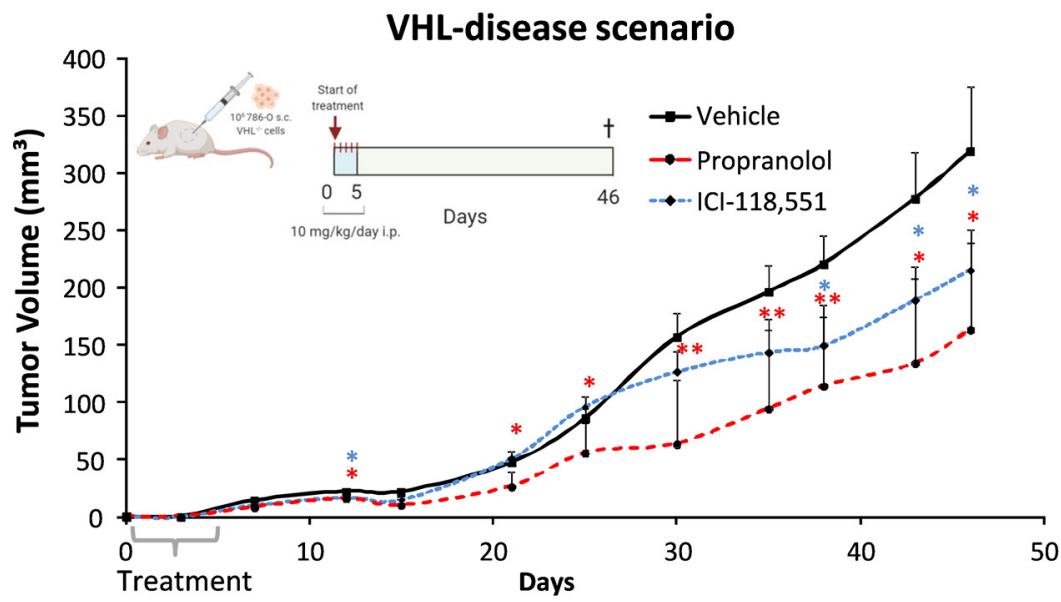

B Classical in vivo cancer research assay

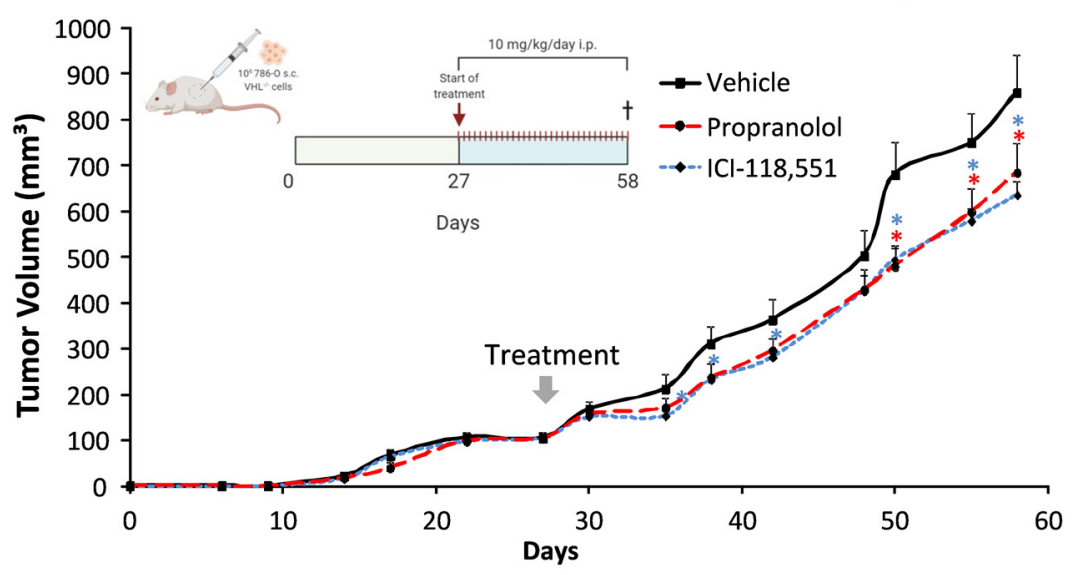

TUMOR WEIGHT

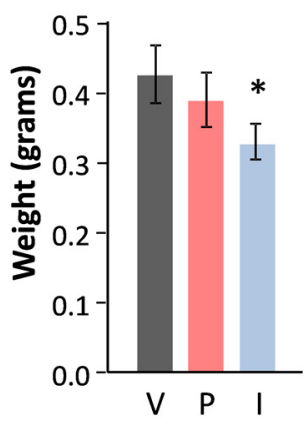

D

\section{HIF- $2 \alpha$}

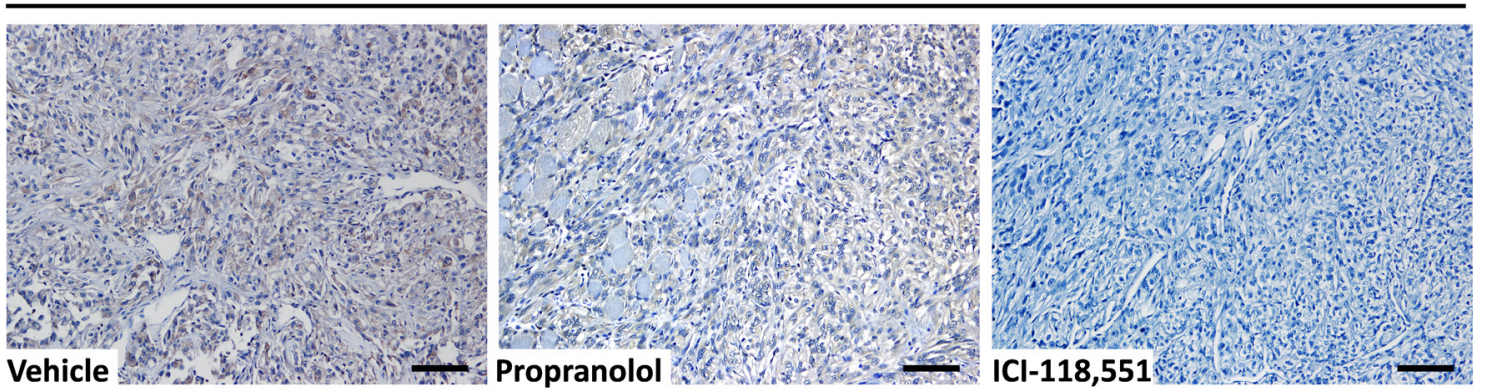

Figure 5. Inhibition of tumor growth by ADRB antagonists. Tumor volumes reached after subcutaneous injections of $10^{6} 786-\mathrm{O}$ wild type cells $(\mathrm{n}=9-10)$ and intraperitoneal treatment with $10 \mathrm{mg} / \mathrm{Kg} /$ day Vehicle $(\mathbf{\square})$, propranolol $(\bullet)$, or ICI $(\diamond)$, in 10-12-week-old male NOD/SCID mice. (A). (VHL-disease scenario) Systemic treatment started along the first five days after tumor implantation; or (B). (Classical in vivo cancer research assay) when average tumor reached $100 \mathrm{~mm}^{3}$ volume. (C). Average weights of the collected tumors. (D). Immunohistochemical detection of HIF- $2 \alpha$ in the ccRCC 786-O tumor xenografts. Cell nuclei were counterstained with hematoxylin. Scale bars represent $100 \mu \mathrm{m}$. (C,D) belong to the "(B). Classical in vivo cancer research assay" approach. Abbreviations: V, P, and I for vehicle, propranolol, and ICI, respectively. Error bars denote \pm SEM for each time. Student's $t$-test: * $p<0.05$; ** $p<0.01 ;{ }^{* * *} p<0.001$. 


\subsection{Data from VHL Patients Treated with Propranolol as Off-Label Prescription}

VHL patients bearing retinal-HB tumors were prospectively treated with propranolol as off-label prescription, following the related literature $[19,20]$ and the orphan drug designation of propranolol for VHL. Table 2 shows the RCC status, up to the present, from 4 VHL patients affected with ccRCC, retinal-HBs, and CNS-HBs. In addition, kidney MRI from the 4 different patients are presented in Figure 6, showing the lesions status when patients started with propranolol treatment, and the follow-up in time, as indicated by the dates. Propranolol-treated patients were followed according to the VHL clinical protocols. All the detected renal lesions were measured. Though we focus on those more significant lesions based on the characteristics and size to assess the treatment requirements. We also considered those cystic lesions feasible to measure in the follow-up. Considering the pathophysiology could be similar to solid tumors, we also observed the propranolol effects in the cystic lesion's growth. Tumor growth was assessed by urologists and radiologists specialized in VHL, through enhanced MRI and/or ultrasound every six months. The treatment prescription, dose adjustment, and clinical monitoring were carried out by an internist with extensive experience in VHL patient management. During the observation time, all patients remained stable, with neither progression of the preexisting ccRCCs nor development of new carcinomas.

Table 2. Clinical monitoring of VHL patients with retinal HBs receiving propranolol in an off-label treatment: previous lesions, dosage, and response to the treatment.

\begin{tabular}{|c|c|c|c|c|c|}
\hline Case & Gender, Age & $\begin{array}{c}\text { Lesions Prior to } \\
\text { Propranolol } \\
\text { Treatment }\end{array}$ & $\begin{array}{c}\text { Propranolol } \\
\text { Treatment Initiation } \\
\text { (months) }\end{array}$ & $\begin{array}{c}\text { Propranolol } \\
\text { Treatment Doses } \\
\text { (mg/kg/day) }\end{array}$ & $\begin{array}{c}\text { Response to } \\
\text { Propranolol } \\
\text { Treatment }\end{array}$ \\
\hline 2 & Male, 24 & $\begin{array}{l}\text { Medulla HB extracted } \\
\text { and partial } \\
\text { nephrectomy due to } \\
\text { ccRCC left } \\
\text { renal lesions }\end{array}$ & $\begin{array}{c}\text { May } 2018 \\
(22 \text { months })\end{array}$ & $\begin{array}{c}\text { Started at } 0.66 \text { and } \\
\text { increased to } 1.2\end{array}$ & $\begin{array}{c}\text { Stable bilateral cystic } \\
\text { lesions after } \\
\text { starting treatment }\end{array}$ \\
\hline 3 & Male, 28 & $\begin{array}{c}\text { Left eye retinal HB, } \\
\text { multiple tumoral and } \\
\text { cystic lesions }\end{array}$ & $\begin{array}{l}\text { August } 2016 \\
\text { (47 months) }\end{array}$ & $\begin{array}{l}\text { Started at } 0.5 \text { and } \\
\text { increased to } 1.4\end{array}$ & $\begin{array}{c}\text { Stable bilateral } \\
\text { lesions but one after } \\
\text { starting treatment }\end{array}$ \\
\hline 4 & Male, 22 & $\begin{array}{c}\text { Right eye retinal HB } \\
\text { and extracted } \\
\text { cerebellum HB }\end{array}$ & $\begin{array}{c}\text { April } 2018 \\
\text { (16 months) }\end{array}$ & 1.8 & $\begin{array}{l}\text { Stable } 3 \text { bilateral } \\
\text { cystic lesions after } \\
\text { starting treatment }\end{array}$ \\
\hline
\end{tabular}

Patient 1: Since she started propranolol treatment 36 months ago, she has not developed any kind of renal lesions along the follow-up. Her mother, also a VHL patient, underwent a total bilateral nephrectomy due to multiple kidney tumors (Figure 6A).

Patient 2: He started propranolol treatment after a partial nephrectomy due to a solid and cystic lesion which resulted in ccRCC and more small bilateral cystic lesions were detected. After 22 months of follow-up, no changes in these cyst lesions have been observed (Figure 6B).

Patient 3: He underwent a bilateral partial nephrectomy before propranolol treatment started. After six months of treatment, a recurrent solid tumor grew from 23.4 to $30.0 \mathrm{~mm}$ in his right kidney which was resected in September 2017. No relapsing or new solid tumors have been detected. Along the 42 months with propranolol treatment, two main cystic lesions in his left kidney were detected, and grew from $12.5 \mathrm{~mm}$ to $15.9 \mathrm{~mm}$, and from $9.0 \mathrm{~mm}$ to $23.2 \mathrm{~mm}$ (Cyst 1 and 2, respectively). None of them exhibited solid component or surgical criteria for VHL at the last control. The rest of the renal parenchyma show multiple small bilateral cystic lesions, remaining stable in the same period (Figure 6C).

Patient 4: 8 months before propranolol treatment initiation, three cystic lesions of 4, 6, and $9 \mathrm{~mm}$ in diameter each were detected. These lesions remain without changes during 16 months of follow-up under propranolol treatment (Figure 6D). 
A
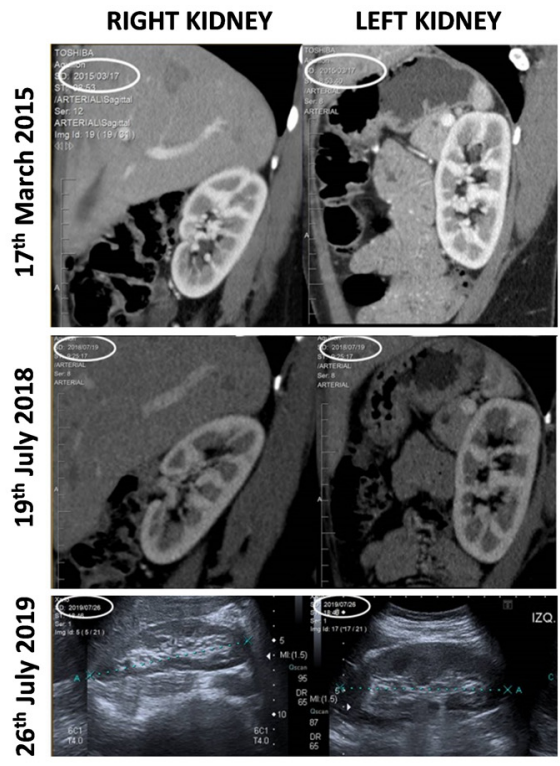

B

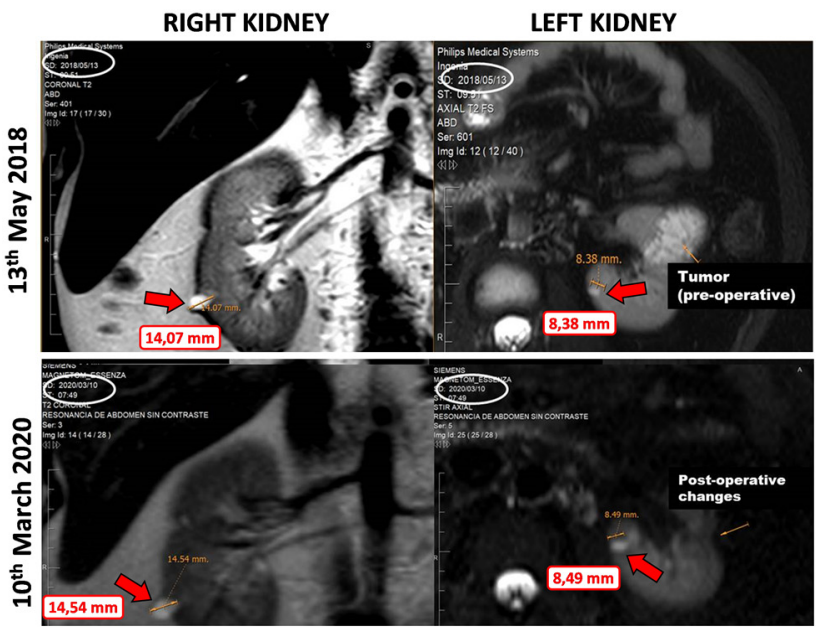

C

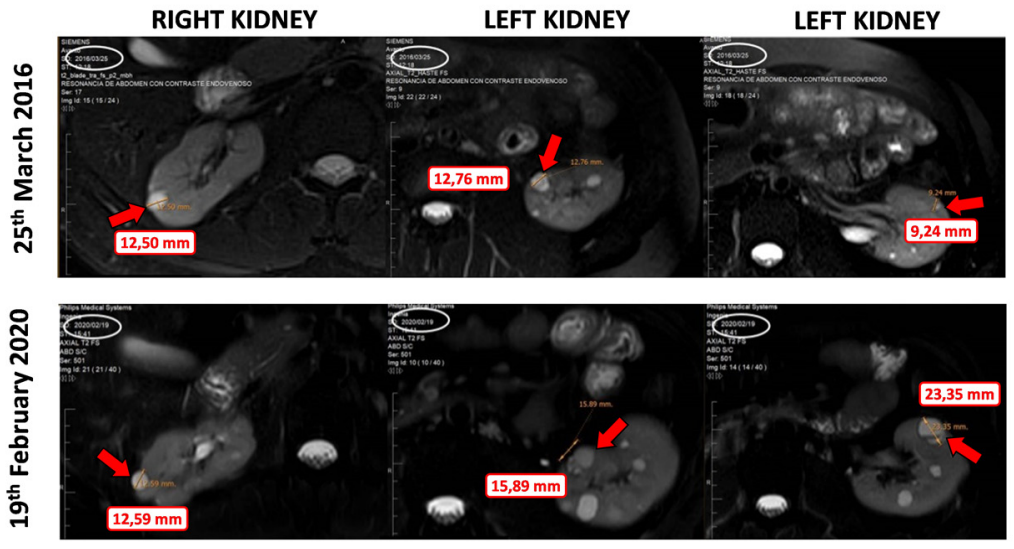

D

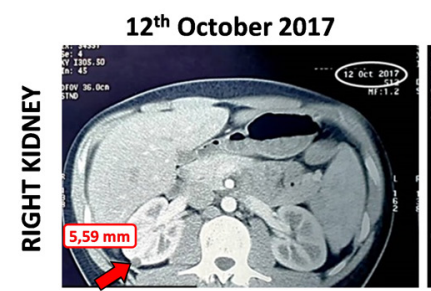

$17^{\text {th }}$ December 2018

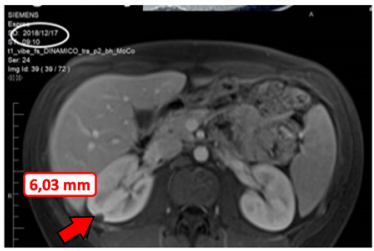

Figure 6. Different images of tumor and cystic lesions evolution in kidneys of VHL patients, before and during propranolol treatment. (A). Patient 1. Female who, after 36 months of treatment, shows no lesions. (B). Patient 2. Male, with a partial nephrectomy due to a solid and cystic lesion diagnosed as ccRCC and small bilateral cystic lesions detected. After 22 months of follow-up, the sizes of the cysts are similar without significant changes. No new tumor has appeared. (C). Patient 3. Male who underwent a bilateral partial nephrectomy before treatment and a tumor growth in his right kidney. No relapsing or new solid tumors have been detected since the treatment. Moreover, his left kidney showed two main cystic lesions, and none of them show surgical criteria, and multiple small bilateral cystic lesions remain. (D). Patient 4. Male, bearing three cystic lesions before propranolol treatment. These lesions remain stable after propranolol treatment.

The main constraint of this study is the limited size of the cohort (comprising 4 VHL patients). However, the data obtained are consistent with the in vitro and in vivo results. These data provide further biological support for the clinical application of $\beta 2$-blockers and their beneficial role in the 
treatment of VHL-related neoplasms. Moreover, the lack of side effects after a systemic and chronic treatment (follow-up ranges from 15 to 47 months) corroborates the safety of use of this drug on VHL patients. Finally, the protective effect of propranolol and other $\beta$-blockers has been reported in other retrospective population-based studies examining hepatocellular carcinoma, prostate cancer, and other malignancies [43].

\section{Discussion}

In VHL patients, a second stochastic event (e.g., missense/nonsense mutation of the VHL gene) ends in a defect or absence of pVHL. Hence, the lack of functional pVHL in VHL patients triggers the initiation of multiple highly vascularized tumors alongside their life span (resulting in an average life expectancy of 59.4 years for males and 48.4 years for females) [44]. In addition, VHL-related mortality is mainly due to complications derived from HB-CNS and ccRCC tumors [44].

Currently, repeated surgeries are the only therapeutic option for VHL patients. Nevertheless, surgeries do not resolve the preoperative neurological deficits since there is a cumulative morbidity in neurologic and retinal functions after each consecutive surgery [45]. After HB-CNS surgical resection, only $20 \%$ of the patients maintain or improve their preoperative symptoms, generating debilitating conditions $[46,47]$. In addition, partial nephrectomy is the only alternative to a complete kidney resection in the case of ccRCCs. Therefore, the lack of therapies for diffuse or recurrent symptoms leads to an urgent demand of effective drugs for VHL patients, especially those that might halt the tumor progression and, subsequently, delay surgical interventions.

To our knowledge, 19 different VHL-related interventional clinical trials have been registered by the U.S. National Library of Medicine and the EU Clinical Trials Register (Table 1). Half of them are exclusively focused on RCC and two-thirds are based on conventional chemotherapeutic drugs, which are able to target rapidly proliferating cells in both normal and cancer tissues: 10 were focused on the role of TKI, mainly sunitinib, sorafenib and pazopanib, and another 5 aimed at blocking VEGF with bevacizumab or its Fab fragment ranibizumab (Table 1).

Most of the systemic therapies assayed have shown limited responses in VHL pancreatic and renal tumors $[14,15]$, while CNS HB had a very low response. Moreover, they are often associated with severe toxicities and side effects, which were often the reason for their discontinuation and termination $[14,15]$.

An appealing alternative would be to identify new therapeutic agents that target vulnerabilities associated with the genetic and epigenetic properties of specific tumor types. In this regard, few of the recent trials target HIF-2 $\alpha$ (PT2799), Hsp90 (17AAG), or $\beta$-adrenergic receptor (propranolol) are aiming to open new strategies for VHL treatment (Table 1). Among them, the selective, small molecule HIF- $2 \alpha$ inhibitor PT2799 has recently reported its results on 61 VHL patients bearing an early stage nonmetastatic ccRCC [34]. The data show a limited response since only 27.9 showed partial response and none showed a complete response; nevertheless, some responses were observed on CNS, retinal, and pancreatic lesions without severe adverse effects as was the case with TKI such as pazopanib (Table 1) $[14,15]$. The authors point to a phase 3 , probably changing their dosage and duration of the trial. This study shows that different strategies than TKI or VEGF-blockers are demanded for VHL.

According to the literature, many different tumors are driven by ADRB receptors [48-50]. Moreover, some papers have shown in vitro the therapeutic benefits of ADRB-2 blockers, counteracting the activation of the receptor [51-53]. Previous works on infantile hemangioma (IH) [54-58] and CNS-HB primary tumors $[16,18]$ demonstrated the in vitro antitumoral effects of propranolol, an ADRB-1,2 blocker. Propranolol, via the $\beta 2$-receptor, triggered apoptosis and decreased HIF levels and its nuclear localization on CNS-HBs $\mathrm{VHL}^{-/-}$primary tumors, as well as the specific ADRB-2 antagonist ICI. Moreover, in a phase III clinical trial conducted in 7 VHL patients harboring retinal HB, tumor growth was halted for the duration of the treatment with propranolol $[19,20]$. These results led to the designation of propranolol as an orphan drug for VHL in 2017 by the European Medicine Agency $(\mathrm{EU} / 3 / 17 / 1841)$. 
ccRCC is the first cause of death in VHL and comprises $63 \%$ of the RCCs in the general population. Both RCCs share a unique and common characteristic: a homozygous mutation in the $V H L$ gene, which drives the stabilization of HIF protein in the resulting tumors, with HIF- $2 \alpha$ being the predominant isoform. [36]. Hence, targeting HIF might have beneficial antitumor effects in both VHL and RCC patients.

Despite the remarkable differences between VHL-HBs and VHL-ccRCCs, such as the type of cells (endothelial vs. epithelial), the common pseudohypoxia state due to loss of functional pVHL makes HBs and ccRCCs suitable for finding common therapeutic strategies. Thus, the purpose of this study was to address whether $\beta 2$-adrenergic antagonists, such as propranolol and ICI, were also effective in ccRCC, as they are in HBs [18], and if the mechanism of action could be similar too.

To the best of our knowledge, this is the first study with primary RCC culture-derived tumors resected from VHL patients (Figure 1A). Additionally, we used the $\mathrm{VHL}^{-1-} 786-\mathrm{O}$ human ccRCC cell line, which represents a useful model to study VHL-related tumors. Using this compendium of line and primary ccRCC cell cultures, we explored the antitumor potential of the two $\beta 2$-blockers, propranolol and ICI.

As in HBs [18], propranolol and ICI showed similar capacity to impair cell proliferation in RCC cells, in a dose-dependent manner, with a LD50 higher than in the 786-O cell line (Figure 1B, Table S1). Figure 1E,F show that apoptosis is the main cause of decreased viability. Two pro-apoptotic genes, $B A X$ and $C A S P 9$, were upregulated after treatment with propranolol and ICI, in agreement with the measurements of caspase 3/7 activity and to the microscopy images of nuclear integrity.

HIFs are probably the most favored molecules in $\mathrm{VHL}^{-/}$cells; free from degradation, they can accumulate and translocate into the nucleus, triggering the expression of a large number of genes [4]. HIF- $2 \alpha$ protein expression was addressed by Western blot in untreated cells or after either $100 \mu \mathrm{M}$ propranolol or ICI treatment. In vitro HIF inhibition was apparently stronger in the 786-O cell line than in the primary tumors after a $\beta 2$-blocker treatment, although a complete effect on a decrease in the HIF- $2 \alpha$ protein levels could not be achieved (Figure 2A). In this context, it is interesting to mention that physapubescin (from Physariumpubescens) has been shown to react with protein thiol-nucleophiles, down-regulating the expression of HIFs and selectively up-regulating the expression of $C H O P$ and DR5 leading to apoptosis in VHL-null RCC [59].

Secretion of VEGF, a direct HIF target, was reduced both in 786-O cells and in VHL-ccRCC primary tumors after $\beta$-antagonists treatment (Figure 2B). Furthermore, the RCC biomarker and direct target of HIF, CAIX, is also downregulated (and in a similar way as with HIF-2 $\alpha$ ) after propranolol or ICI treatment. This result correlates with our previous findings in HBs $[16,18]$ indicating that the mechanism of action in RCCs is similar to that observed in HBs, and that in both cases we are interfering with a common link: the constitutively active HIF proteins, interfered by the $\beta 2$-adrenergic blockers.

Propranolol and ICI also exerted gene expression changes in different VHL-ccRCCs, such as the already mentioned pro-apoptotic genes $B A X$ and $C A S P 9$ and the HIF target gene $A Q P-1 . A Q P-1$ is of special interest in VHL-HBs since $A Q P-1$ encodes a transmembrane water channel protein [37-39]. $A Q P-1$ expression is induced by HIFs and its enhanced expression may increase liquid flow across the cell membrane, leading to cystic growth, commonly described in VHL tumors. The observation of a significantly decreased $A Q P-1$ expression, similar to the observed in HBs [18], would lead to slowing down of the cystic growth surrounding the tumor. In addition, $A D R B-2$ expression itself was downregulated by both propranolol and ICI (Figure 2C and Figure S2), indicating that ccRCCs can be targetable tumors by $A D R B-2$ antagonists. It is worth noting that $A D R B-1$ is not expressed by the ccRCCs, according to our PCRs results (Figure S3).

Considering that ADRB-2 antagonists reduced HIF levels, and significantly inhibited HIF target genes (such as VEGF, AQP-1, and CAIX), HIF-2 $\alpha$ subcellular distribution had to be addressed. We had previously reported that HIF- $1 \alpha$ nuclear internalization on CNS-HBs and primary HUVECs under chemical hypoxia was impaired after treatment with $\beta 2$-blockers [18]. Here, we confirm that after propranolol or ICI treatment, HIF- $2 \alpha$ nuclear translocation was similarly impaired (by $24 \%$ and $21 \%$, 
respectively) (Figure 3). Although we cannot formally confirm it, it seems reasonable to speculate that changing the subcellular localization of HIF- $2 \alpha$ and thus their transcriptional activity, could lead to a clinical improvement in RCC tumor patients [60]. Unlike HIF-1 $\alpha$, HIF-2 $\alpha$ also plays a major role in the tumor cytoplasm. Thus, Uniacke et al. demonstrated that HIF- $2 \alpha$ can form a complex in the cytoplasm to help the initiation of protein synthesis in periods of oxygen scarcity $[57,61]$. This mechanism was shown to be especially important for tumor development as it allows the tumor cells to overcome the hypoxia-induced repression of protein translation, which can explain the correlation between high HIF- $2 \alpha$ cytoplasmic abundance and unfavorable prognosis in RCC patients. Although the data here shown throws light on the presence and distribution of HIF- $2 \alpha$ on RCCs, the exact molecular mechanism by which HIF- $2 \alpha$ is contributing to VHL-RCC malignancy remains unresolved.

On the other hand, hypoxia or a pseudo-hypoxic status caused by absence of VHL expression, induces the activity of the $N F \kappa B$ pathway - another major molecular pathway triggered to mediate cellular responses upon hypoxic stimuli. $N F \kappa B$ induced by hypoxia can independently upregulate many inflammatory genes and directly induce HIFs gene expression [58,62]. Although the mechanism underlying $N F \kappa B$ activation by hypoxia remains elusive, one well-accepted mechanism is that, under hypoxic conditions, inhibition of $N F \kappa B$ is activated by IKK-mediation $[59,63]$. In any case, the combination of both programs - the HIF genes and the inflammatory antiapoptotic program triggered by $N F \kappa B$ activation - may contribute to tumor malignancy and drug resistance. Therefore, the ideal anti-tumoral drug should tackle both HIFs and NFkB pathways. In the study here presented, by means of immunofluorescence microscopy, propranolol and ICI show a significant reduction of the nuclear translocation of p65 (32\% and 43\%, respectively) (Figure 4A). Altogether, ADRB-2 antagonists have proven to be able to reduce the translocation of HIF- $2 \alpha$ and p65, master transcription regulatory keys of both pathways. IL-1 $\beta$, IL-6, and TNFAIP6 are known targets of p65, the inflammatory program led by NFkB [58,62]. Propranolol or ICI treatments significantly decreased the expression of these p65 target-genes as observed by q-PCR (Figure 4B), which confirms the highly promising therapeutic properties of the tested ADRB-2 antagonists.

Results of our two in vivo xenograft experiments with 786-O cells on NSG mice suggest that propranolol and ICI slow down tumor progression in two different approaches: (i) early short-time treatment ("prevention setting") (Figure 5A) and (ii) treatment of an established tumor ("therapeutic setting") (Figure 5B). Propranolol and ICI delayed tumor growth by up to seven and ten days, creating a therapeutic time window with applications in a clinical scenario for further surgeries or combinatorial therapies. The delay in the tumor establishment and tumor growth in vivo may be explained by a decrease in serum VEGF-A levels. This decrease may be of human origin (from the 786-O cells) and of murine origin (induced by the tumor cells in surrounding stroma). In this way, propranolol and ICI may have a direct anti-tumor effect by inducing apoptosis. This fact has been supported by the observed induction of $B A X-2$ and CASPs 3/7/9, as also previously shown in HBs [16,18]. Additionally, $\beta 2$-blockers may also induce systemic changes that lead to a poorly adequate tumor microenvironment. On one hand, $\beta$-adrenergic antagonists are acting as pro-apoptotic, and on the other hand, they act as anti-angiogenic agents by reducing HIF activity and therefore leading to a downregulation of HIF targets like CAIX and VEGF. Plasma VEGF levels were recently reported to serve as a reliable biomarker in patients with VHL taking propranolol for retinal HBs $[19,20]$. While tumors remained stable, VEGF plasma levels in VHL patients decreased to standard levels during the treatment, in agreement with our in vitro and in vivo findings.

In addition, our prospective analysis of ccRCC growth kinetics in VHL patients with retinal tumors receiving propranolol treatment in an off-label use, following the results of Albiñana et al. [19], revealed a stable status with cessation of growth of RCCs during the whole period of propranolol treatment (Table 2). Considering the cardiovascular symptoms of propranolol, its dose escalation was based on the tolerance of hypotension or bradycardia. An increase of $20-40 \mathrm{mg}$ in the dose of propranolol happened when the cardiac rate was higher than 60 per minute and the arterial pressure 
was equal to or higher than 100/60 mmHg in absence of symptoms. Moreover, presence of other symptoms like fatigue or sleep deprivation nightmares was studied.

The measurements were made by VHL-trained radiologists belonging to the VHL Unit at Hospital Italiano de Buenos Aires (Argentina). The patients had been imaged by 320 CTMS or 3.0 Tesla Ingenia Siemens MRI (Siemens, Erlangen, Germany) and the findings were discussed in multidisciplinary clinical meetings in which a detailed comparison with previous tests was carried out (Figure 6).

For this prospective study, we have considered "stable" cases when the lesion growth is not significant in a period between 6-12 months, especially when the size of the lesions does not require a surgical treatment. However, we cannot know about the natural history of each lesion in these patients without propranolol. Despite this, it seems that the lesions tend to have a slower growth, especially in patient 1 , sharing a mutation that provoked a total bilateral nephrectomy for her mother but no tumor growth for her, and in patient 3 who has a history of several and fast growth lesions in the past.

Despite the limited group size and the lack of a priori strategy, these data are not conclusive but consistent with our cell culture and in vivo studies and thus provide further rationale for using propranolol in the treatment of VHL-related neoplasms. The follow-up of the presented 4 cases and the search for new data from more VHL patients is urgent, and the commitment will be made. Moreover, the protective effect of propranolol, previously described by us for CNS-HB [16,18], was supported by Shepard et al. in 2018 [36]. Lastly, other $\beta$-blockers have been reported in other retrospective population-based studies examining hepatocellular carcinoma, prostate cancer, and other malignancies [43].

Propranolol shares affinity for ADRB- 1 and -2 and therefore comes with the disadvantage of cardio-specific side effects. Hence, a highly specific ADRB-2 antagonist may be the ideal compound to treat VHL patients, as it would maintain the therapeutic properties of propranolol while avoiding its hypotension and bradycardia effects. Thus, since we have shown clear in vitro differences in LD50 between non-cancerous cells and ccRCC cultures, and no undesirable side effects have been observed in either animal models or clinical trials [18], we believe it would be beneficial to initiate ICI for clinical use and even try applying escalating doses.

The blockade of the ADRB-2 pathway opens a new strategic avenue for the anti-tumor treatment spectrum. Overall, TKIs have shown limited response in VHL patients, particularly in ccRCC, where a $42 \%$ partial response has only been reported in one of the latest trials [15]. Since ADRB-2 blockers (similar to TKIs) primarily act as antiangiogenics, a combination of TKIs and ADRB-2 blockers might have synergic effects, improving the results of individual treatments. On the other hand, in aggressive and metastatic tumors, a combination of intercalating agents targeting cellular division with ADRB-2 blockers might reduce metastatic dissemination, as has been recently shown in metastatic paraganglioma $[60,64]$.

Remarkably, ADRB-2 blockers target receptors on the surface of the cells and, in contrast to TKIs and intercalating agents, their internalization is not required. This is an added advantage since this will prevent from the development of multidrug resistance mechanisms (MDR) such as by ABC transporters, controlling drug exclusion from the cancer cells. These mechanisms should not be operative with ADRB-2 blockers. In this respect, preliminary results obtained by our group have shown a limited resistance of 786-O cells to propranolol. Gene expression of the few resistant cells was analyzed by RT-qPCR, supporting a decrease in expression of MDR genes (Figure S2). Thus, the only expected mechanism of resistance to ADRB-2 blockade could be a decrease in the expression levels of ADRB-2 receptors, as it is demonstrated in Figure S3. However, as reported, many tumors are driven through ADRB-2 activation $[48-50,61,65]$, and a decrease in the receptor expression would lead, in turn, to a decrease in tumorigenicity [51-53].

In summary, these findings demonstrate for the first time that ADRB-2 antagonists could be used as promising therapeutic agents to treat RCCs, acting through inhibition of cancer cell proliferation, tumor angiogenesis, and inflammation (Figure 7). These findings support further implementation of 
$\beta$-blockers into the clinic as a promising new treatment for VHL and other non-VHL tumors that share molecular similarities with VHL.

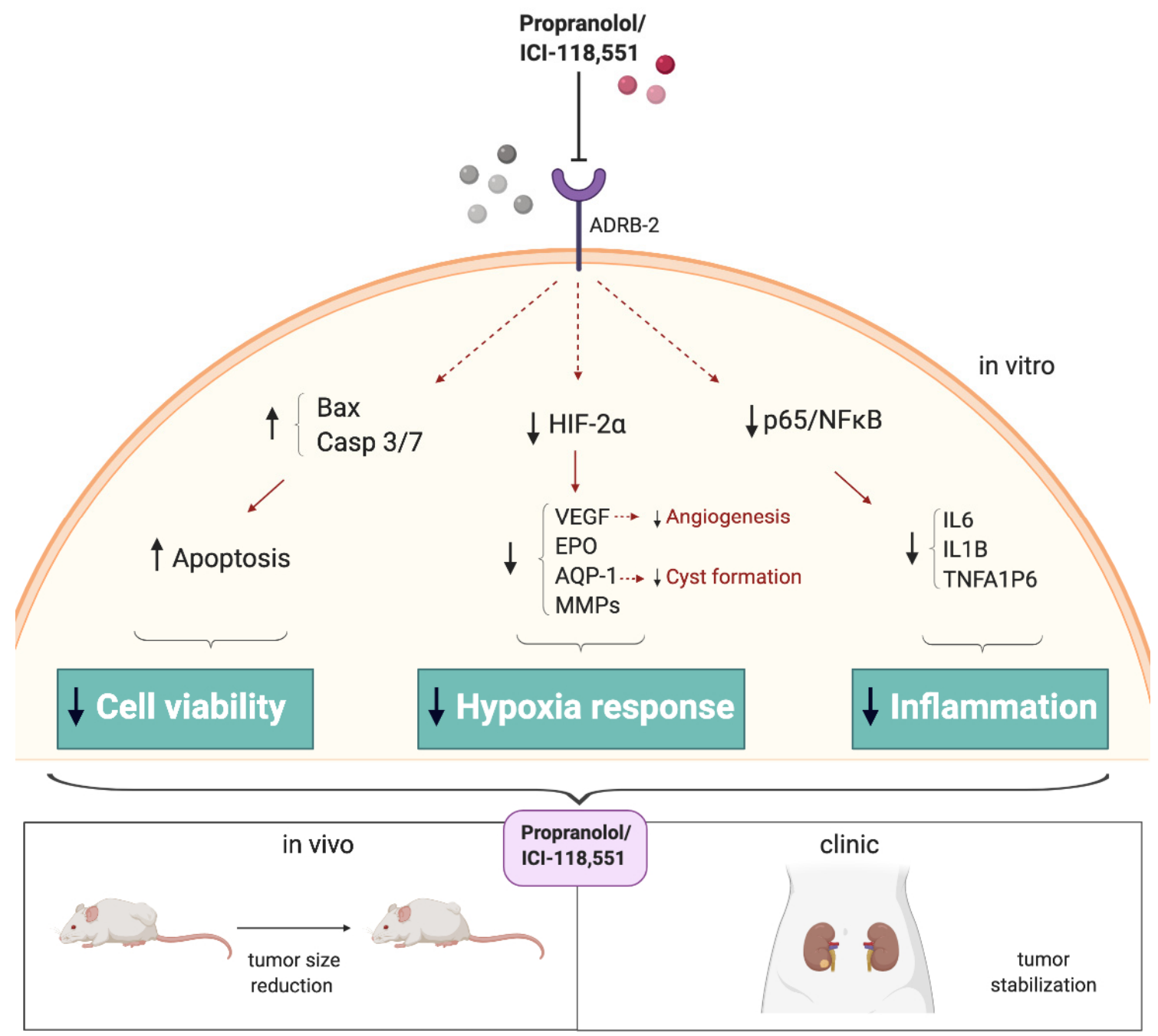

Figure 7. Antitumor benefits shown by ADRB-2 antagonists in VHL-derived ccRCC. Propranolol and ICI-118,551 have shown therapeutic benefits both in vitro and in vivo-on ccRCCs, by triggering key processes like apoptosis, increasing Bax or Caspases 3/7 expression, targeting and impairing the expression and signaling of molecules such as HIF and its targets, and decreasing NFkB/p65 signaling, showing anti-tumoral effects in vivo. ADRB-2 antagonists could be used as promising therapeutic agents to treat RCCs, acting through inhibition of cancer cell proliferation, tumor angiogenesis, and inflammation.

\section{Materials and Methods}

\subsection{Ethics Approval and Consent to Participate}

All methods were carried out in accordance with Consejo Superior de Investigaciones Científicas CSIC and Spanish guidelines and regulations. All experimental protocols were approved by the CSIC Ethical Committee (code 075/2017), including human samples handling, and were done following the guidelines of the World Medical Assembly (Declaration of Helsinki). Animal experiments were approved by both CSIC committee of animal welfare and Madrid animal experimental committee (PROEX 045/17). Both institutions follow the "Ethical Principles and Guidelines for Experiments on Animals" from the Swiss Academy of Medical Sciences (SAMS) and the Swiss Academy of Sciences (SNAT). 
Informed consent was obtained from all subjects whose surgical surplus were utilized to generate primary tumor cultures. All primary tumors derived from human samples are part of a clinical data collection registered at the Instituto de Salud Carlos III (ISCIII).

\subsection{Cell Culture and Treatments}

Clear cell renal cell carcinoma primary tumor cultures (ccRCC) were obtained from surplus of resected surgery tumor samples from VHL patients following the procedure previously described (16), and cultured in RPMI medium supplemented with $20 \%$ fetal bovine serum (FBS), 2 mM L-glutamine, and $100 \mathrm{U} / \mathrm{mL}$ penicillin/streptomycin (all from GIBCO, Grand Island, NY, USA). All patients provided written informed consent to use their tissue samples for this study.

HUVECs (ATCC-CRL-1730) were cultured in EGM-2 (Lonza, Walkersville, MD, USA) supplemented with 10\% FBS, $2 \mathrm{mM}$ L-glutamine, and $100 \mathrm{U} / \mathrm{mL}$ penicillin/streptomycin (GIBCO, Grand Island, NY, USA).

The human renal cancer cell line 786-O (ATCC CRL-1932) was cultured in RPMI supplemented with 20\% FBS, $2 \mathrm{mM}$ L-glutamine, and $100 \mathrm{U} / \mathrm{mL}$ penicillin/streptomycin.

ccRCC primary tumors, 786-O cells, and HUVECs were incubated with different doses of ADRB antagonists for the time and dose indicated in each experiment. Atenolol (Sigma-Aldrich, St. Louis, MO, USA) was dissolved in DMSO (Merck, Darmstadt, Germany), while propranolol and ICI (Sigma-Aldrich, St. Louis, MO, USA) were dissolved in distilled water.

All the cellular assays were performed at $37^{\circ} \mathrm{C}, 5 \% \mathrm{CO}_{2}$ and humidity conditions.

\subsection{Cell Viability Assay}

The viability of the ccRCC primary tumors, 786-O cells, and HUVECs was measured using the "Luminescent Cell Viability Assay" (Promega, Madison, WI, USA). This is a homogeneous quantitative method to determine the number of viable cells in culture based on quantitation of the ATP presence, which indicates metabolically active cells.

A total of 5000 cells/well were plated in 96-well plates and cultured in $100 \mu \mathrm{L}$ with [0- 25- 50- 100and $200 \mu \mathrm{M}$ ] propranolol or ICI for $72 \mathrm{~h}$. Then, $100 \mu \mathrm{L} /$ well of Cell Titer-Glo reagent (Lysis buffer, Ultra-Glo Recombinant Luciferase, Luciferine and $\mathrm{Mg}^{2+}$ ) was added and gently mixed for $15 \mathrm{~min}$ at RT. Finally, luminescence was measured using a Glomax Multidetection System (Promega, Madison, WI, USA) [16,18].

\subsection{Caspase Activation Assay}

The Caspase-Glo ${ }^{\circledR}$ 3/7 Assay (Promega, Madison, WI, USA) is a luminescent assay that measures caspase- 3 and caspase- 7 activities by using a luminogenic caspase-3/7 substrate composed of the tetrapeptide sequence DEVD, luciferase, and cell lysis buffer. Therefore, the luminescence generated is proportional to the amount of active caspase presence.

A total of 5000 cells/well were plated in 96-well plates and cultured in $100 \mu \mathrm{L}$ with [0- 25- 50- 100and $200 \mu \mathrm{M}$ ] propranolol or ICI for $72 \mathrm{~h}$. Then, $100 \mu \mathrm{L} /$ well of Caspase Glo ${ }^{\circledR}$ 3/7 Reagent (Promega, Madison, WI, USA) (Lysis buffer, Ultra-Glo Recombinant Luciferase, DEVD-aminoluciferine, and $\mathrm{Mg}^{2+}$ ) was added and gently mixed for $1 \mathrm{~h}$ at RT. Finally, luminescence was measured using a Glomax Multidetection System (Promega, Madison, WI, USA) [16,18].

\subsection{Real-Time Quantitative PCR}

Total RNA was extracted from cell cultures using Nucleo Spin RNA kit (Macherey-Nagel, Düren, Germany). One microgram of total RNA was reverse-transcribed in a final volume of $20 \mu \mathrm{L}$ with High Capacity cDNA Reverse Transcription Kit supplemented with an RNase Inhibitor (Thermo Fisher Scientific, Vilnius, Lithuania) using random primers. FastStart Essential DNA Green Master (ROCHE, Mannheim, Germany) was used to carry out real-time PCR using an iQ5 system (BioRad, Foster City, CA, USA). Table 3 shows primers used for q-PCR. 
Table 3. Primers used for q-PCR assays.

\begin{tabular}{|c|c|}
\hline Gene & Sequence \\
\hline 18S Fwd & 5'-CTCAACACGGGAAACCTCAC-3' \\
\hline $18 S \operatorname{Rev}$ & 5'-CGCTCCACCAACTAAGAACG-3' \\
\hline$A D R B-1$ Fwd & 5'-GTGGAAGATGGGTGGGTTAG-3' \\
\hline$A D R B-1$ Rev & 5'-GAGCCACGATGATCGATTTTA-3' \\
\hline$A D R B-2$ Fwd & 5'-CCATGTCCAGAACCTTAGCC-3' \\
\hline$A D R B-2$ Rev & 5'-GATCTGCGGAGTCCATGC -3’' \\
\hline$A Q P-1$ Fwd & 5'-GGAGGGTCCCGATGATCT-3' \\
\hline$A Q P-1 \operatorname{Rev}$ & 5'-CCTCCCTGACTGGGAACTC-3' \\
\hline$B A X$ Fwd & 5'-CACTCCCGCCACAAAGAT-3' \\
\hline$B A X \operatorname{Rev}$ & 5'-CAAGACCAGGGTGGTTGG-3' \\
\hline CAIX Fwd & 5'-TGCCGTCAATTAAGCATAAGG-3' \\
\hline CAIX Rev & 5'-GTCCAGTAATCTGGGCAGGTA'-3 \\
\hline CASP9 Fwd & 5'-CCCAAGCTCTTTTTCATCCA-3' \\
\hline CASP9 Rev & 5'-TTACTGCCAGGGGACTCGT-3' \\
\hline IL-6 Fwd & 5'-CAGGAGCCCAGCTATGAACT-3' \\
\hline IL-6 Rev & 5'-GAAGGCAGCAGGCAACAC-3' \\
\hline$I L-1 \beta$ Fwd & 5'-CTGTCCTGCGTGTTGAAAGA-3' \\
\hline$I L-1 \beta \operatorname{Rev}$ & 5'-TTGGGTAATTTTTGGGATCTACA-3' \\
\hline TNFAIP6 Fwd & 5'-GGCCATCTCGCAACTTACA-3' \\
\hline TNFAIP6 Rev & 5'-GCAGCACAGACATGAAATCC-3' \\
\hline MDR Fwd & 5'-TTGAAATGAAATGTTGTCTGG-3' \\
\hline MDR Rev & 5'-CAAAGAAACAACGGTTCGG-3' \\
\hline
\end{tabular}

\subsection{Western Blot Analysis for HIF-2 $\alpha$}

Primary ccRCC tumor cultured cells and the 786-O ccRCC cell line were incubated with $100 \mu \mathrm{M}$ propranolol, ICI, or vehicle for $48 \mathrm{~h}$. Then, cells were lysed on ice for $30 \mathrm{~min}$ in TNE buffer (50 $\mathrm{mM}$ Tris, $150 \mathrm{mM} \mathrm{NaCl}, 1 \mathrm{mM}$ EDTA, and $0.5 \%$ Triton X100 (Sigma-Aldrich, St. Louis, MO, USA) supplemented with wide-range protease inhibitors (Roche, Basel, Switzerland) and lactacystin (Sigma-Aldrich, St. Louis, MO, USA), a specific proteasome inhibitor to preserve HIF integrity. Lysates were centrifuged at 14,000 $\mathrm{g}$ for $5 \mathrm{~min}$. Similar amounts of protein from cleared cell lysates were boiled in SDS sample buffer and analyzed by 4-20\% SDS-PAGE under non-reducing conditions (BioRad, Foster City, CA, USA). Proteins from gels were electro-transferred to nitrocellulose membranes (Amersham, Little Chalfont, UK) followed by immunodetection with anti-HIF-2 $\alpha$ (NOVUS, Oxon, UK) and anti-actin (Sigma-Aldrich, St. Louis, MO, USA) antibodies. Following primary antibody incubation, samples were washed and incubated with the corresponding horseradish peroxidase-conjugated secondary antibodies from Dako (Glostrup, Denmark). All antibodies were used at the dilution recommended by the manufacturer. Membranes were developed by chemiluminescence (SuperSignal West Pico Chemiluminescent Substrate, Thermo Scientific, Rockford, IL, USA).

\subsection{VEGF Determination}

Quantikine Human VEGF ELISA kit from R \& D Systems (R \& D, Abingdon, UK) was used to quantitatively determine human VEGF concentrations in supernatants from ccRCC primary tumors and 786-O cell line treated with vehicle or $100 \mu \mathrm{M}$ propranolol or ICI for $48 \mathrm{~h}$.

\subsection{Immunofluorescence Microscopy}

Immunofluorescence analyses were performed to evaluate the effect of propranolol and ICI on the subcellular distribution of HIF- $2 \alpha$ and p65, and to examine the expression of CAIX, a cell marker 
of ccRCCs. Therefore, $5 \times 10^{3} 786-\mathrm{O}$ cells were seeded on sterile coverslips (13 mm diameter, VWR international, Radnor, PA, USA) placed at the bottom of a 24-well plate. On the next day, cells were treated with $100 \mu \mathrm{M}$ either propranolol or ICI for $48 \mathrm{~h}$.

Then, cells were washed with PBS and fixed with 3\% paraformaldehyde (PFA) for $10 \mathrm{~min}$ at RT. After two PBS washing steps, samples were incubated with blocking solution (1\% goat serum and $1 \%$ BSA in PBS) for $1 \mathrm{~h}$ at RT.

Cells were incubated overnight at $4{ }^{\circ} \mathrm{C}$ with mouse anti-human HIF-2 $\alpha$ (1:100) (NOVUS), p65 (1:400) (Cell Signaling, Danvers, MA, USA), or CAIX (1:100) (Dako, Santa Clara, CA, USA). Following this, cells were washed thoroughly four times with PBS and incubated for $1 \mathrm{~h}$ at RT with goat anti-Mouse IgG (H+L)-Alexafluor 568-conjugated antibody (1:200) (Thermo Fisher Scientific, Waltham, MA, USA). Finally, cells were washed with PBS and coverslips were mounted on glass slides using Prolong+DAPI mounting media (Molecular Probes, Eugene, OR, USA). Using the fluorescence confocal microscope SP5 (DMI6000 CS Leica Microsystems, Wetzlar, Germany), 40× confocal images were taken. Green, red, and blue channels represent HIF-2 $\alpha /$ p65, CAIX, and DAPI stains, respectively.

For the subcellular distribution determination, DAPI nuclear signal was used to fix the upper and lower sample limits (z-axis) and $1 \mu \mathrm{m}$ z-stacks were programmed. After a maximum intensity projection, DAPI signal was used to identify and distinguish the nuclear limits and the HIF- $2 \alpha$ or p65 signal to identify the cellular limits.

FIJI-ImageJ software (NIH, MD, USA) was used to measure the fluorescent intensities as follows. Using the HIF- $2 \alpha$ or p65 signal, a straight line alongside the longer diameter and crossing the cell nuclei was traced and its intensity were measured (the whole cell signal). Then, using the nuclear limits, the very same line was shortened to reach just the nuclei and its fluorescence intensity was again measured (nuclear signal). Finally, the whole cell signal was normalized to $100 \%$ and, using the nuclear signal, the ratio nucleus/cytoplasm percentage was rated.

For CAIX expression levels, DAPI nuclear signal was used to fix the upper and lower sample limits (z-axis) and $1 \mu \mathrm{m}$ z-stacks were programmed. After a maximum intensity projection, individual CAIX cell intensity was measured using FIJI-ImageJ software (NIH, MD, USA). Finally, the PBS group cell signal was normalized to $100 \%$ and the intensities from the cells treated either with propranolol or ICI rated.

\subsection{In Vivo Tumor Xenografts}

In order to address the antitumor properties of $\beta$-blockers, two different heterotopic in vivo approaches were employed. Both animal experiments were performed according to the approved in vivo experimental procedure PROEX 045/17.

In the first in vivo study, $10^{6} 786-\mathrm{O}$ cells were subcutaneously injected in the dorsal flank of 7-8-week-old NOD scid gamma (NSG ${ }^{\mathrm{TM}}$ ) male mice (kind gift of Dr Garcia-Sanz JA, own breeding, originally from The Jackson laboratory, Bar Harbor, ME, USA). On the next day and during the first five consecutive days after implantation, two groups were treated intraperitoneally either with $10 \mathrm{mg} / \mathrm{kg}$ body propranolol, ICI-118,551, or Vehicle (9-10 mice per group). Tumor growth was measured twice by a caliper every $2-3$ days and volumes were calculated according to the formula: shortest $t^{2} \times$ largest $\times 0.52$. Mice were sacrificed when the control group (Vehicle) reached an end point established according to ethical procedures.

In the second in vivo experiment, $10^{6} 786-\mathrm{O}$ cells were subcutaneously injected in the dorsal flank of 7-8-week-old NSG ${ }^{\mathrm{TM}}$ male mice. Tumor growth measurements and calculations were assessed as mentioned above. When average tumor volume reached $100 \mathrm{~mm}^{3}$, the mice were randomly divided in 3 groups (9-10 mice per group) and each group was daily treated intraperitoneally with either $10 \mathrm{mg} / \mathrm{Kg}$ body propranolol, or ICI-118,551, or Vehicle for 20 more days. The mice were euthanized when the control group (Vehicle) reached an end point established according to ethical procedures. 


\subsection{Immunohistochemistry}

HIF-2 $\alpha$ expression from tumor xenografts was evaluated in paraffin-embedded tumor xenografts belonging to the "Classical in vivo cancer research assay". The immunohistochemical staining was done in $5 \mu \mathrm{m}$ deparaffined and hydrated sections. Sections were incubated with an anti-HIF-2 $\alpha$ antibody (1:600) (NOVUS, Oxon, UK). Then, samples were washed and incubated with HRP-conjugated secondary mouse anti-human antibody. HRP activity was amplified with DakoEn Vision + Dual Link System-HRP (Dako, Santa Clara, CA, USA) and the visualization was performed with a DAB substrate Kit (Dako, Santa Clara, CA, USA). Samples were counterstained with hematoxylin $0.02 \%$ and mounted with DPX mounting medium (Sigma-Aldrich, St. Louis, MO, USA). Images were taken at $10 \times$ with an Olympus digital camera (Olympus, Hamburg, Germany) coupled with an Axio Vert A1 Zeiss microscope (Zeiss, Jena, Germany). The Vehicle group was tested as positive control and negative controls were performed in parallel, with omission of the primary antibody incubation step.

\subsection{Clinical Data from Patients}

We conducted a retrospective analysis of patients who were treated with propranolol because of a retinal HB but also bearing a ccRCC. Their medical histories were analyzed in order to determine whether the treatment with propranolol influenced the renal tumor development and progression. Hence, parameters like propranolol dosage, treatment duration, tumor growth, recurrence after resection and metastases diagnosis have been collected and studied.

\subsection{Statistical Analysis}

Results are presented as mean \pm SEM. Statistical analyses were performed using Student's $t$-test. Statistical significance was defined when $p<0.05\left({ }^{*} p<0.05 ;{ }^{* *} p<0.01\right.$, and $\left.{ }^{* * *} p<0.001\right)$.

\section{Conclusions}

VHL-ccRCC, the second cause of death in VHL patients, lacks an effective systemic treatment, with recurrent surgeries being the only effective solution. The ADRB-2 antagonists propranolol and ICI-118,551 have shown therapeutic benefits on ccRCC in vitro and in vivo-triggering key processes like apoptosis, targeting and impairing the expression and signaling of key molecules such as HIF and $\mathrm{NFkB} / \mathrm{p} 65$, and showing anti-tumoral effects in vivo. In addition, clinical data show a better outcome of VHL-ccRCC patients after propranolol off-label treatment.

Propranolol and ICI-118,551 have shown antitumor benefits in VHL-derived ccRCC, and since ccRCC s comprise 75\% of the total RCCs, targeting ADRB-2 becomes a promising drug for VHL and other non-VHL tumors.

Supplementary Materials: The following supplementary materials are available online at http://www.mdpi. com/2077-0383/9/9/2740/s1, Figure S1. Representation of the q-PCR cycle amplification of cDNA for CAIX in ccRCC,786-O, and HUVECs. Figure S2. mRNA quantification of ADRB-2 and MDR in propranolol-treated 786-O cells. Figure S3: Representation of the q-PCR cycle amplification of cDNA from ADRB-1, ADRB-2, and 18S in ccRCC primary cultures. Table S1: propranolol and ICI-118,551 LD50 dosages for 786-O, HUVEC and ccRCC primary cultures and cell lines.

Author Contributions: Conceptualization, L.M.B. and A.M.C.; methodology, L.M.B., A.M.C., V.A., E.G.-V., L.R.-P., I.d.R.-P., A.C.-C., P.G.-P. and T.A.; software, V.A.; validation, L.M.B., A.M.C. and V.A.; formal analysis, L.M.B., A.M.C., V.A., E.G.-V., I.d.R.-P. and T.A.; investigation, L.M.B., A.M.C. and V.A.; resources, T.A. (in vivo assays), D.T.A., M.M.S. and L.M.-P. (surgical surplus and clinical data); data curation, L.M.B., A.M.C. and V.A.; writing-original draft preparation, L.M.B., A.M.C. and V.A.; writing-review and editing, L.M.B., A.M.C., V.A., E.G.-V., I.d.R.-P., T.A., D.T.A., M.M.S. and L.M.-P.; visualization, L.M.B., A.M.C., V.A., E.G.-V. and I.d.R.-P.; supervision, L.M.B. and A.M.C.; project administration, L.M.B.; funding acquisition, L.M.B. All authors have read and agreed to the published version of the manuscript.

Funding: This research was funded by Ministry of Economy and Competitivity, grant number SAF2017-83351-R. L.M-P. was supported by grants from Madrid Regional Government "IMMUNOTHERCAN" [B2017/BMD-3733-2]. A.M.C. was funded by the Spanish Alliance of VHL patients and V.A. was funded by CIBERER. 
Acknowledgments: The authors want to thank in the first place the Spanish Alliance of VHL, for direct support, inspiration, and help from the patients who donated surgical surplus for our research. We are also indebted to the physicians who performed the surgeries and provided clinical data. The authors feel extremely grateful to José-Alberto García Sanz (Biological Research Center Margarita Salas) for providing animals and helpful critical reading of the manuscript. We also appreciate the critical reading of the manuscript by Omelyan Trompak (University Hospital Tübingen). We thank Jose Luis Fortes Alen (Hospital Universitario Fundación Jiménez Díaz) for his help on searching for VHL patients. Finally, we thank Noelia Napoli (Hospital Italiano de Buenos Aires) for the clinical images acquisition.

Conflicts of Interest: The authors declare no conflict of interest.

\section{References}

1. Ferlay, J.; Colombet, M.; Soerjomataram, I.; Dyba, T.; Randi, G.; Bettio, M.; Gavin, A.; Visser, O.; Bray, F. Cancer incidence and mortality patterns in Europe: Estimates for 40 countries and 25 major cancers in 2018. Eur. J. Cancer 2018, 103, 356-387. [CrossRef] [PubMed]

2. Kaelin, W.G. Molecular basis of the VHL hereditary cancer syndrome. Nat. Rev. Cancer 2002, 2, 673-682. [CrossRef] [PubMed]

3. Shuin, T.; Yamasaki, I.; Tamura, K.; Okuda, H.; Furihata, M.; Ashida, S. Von Hippel-Lindau disease: Molecular pathological basis, clinical criteria, genetic testing, clinical features of tumors and treatment. Jpn. J. Clin. Oncol. 2006, 36, 337-343. [CrossRef] [PubMed]

4. Maher, E.R.; Neumann, H.P.H.; Richard, S. Von Hippel-Lindau disease: A clinical and scientific review. Eur. J. Hum. Genet. 2011, 19, 617-623. [CrossRef]

5. Bader, H.L.; Hsu, T. Systemic VHL gene functions and the VHL disease. FEBS. Lett. 2012, 586, $1562-1569$. [CrossRef]

6. Lefebvre, M.; Foulkes, W.D. Pheochromocytoma and paraganglioma syndromes: Genetics and management update. Curr. Oncol. 2014, 21, e8-e17. [CrossRef]

7. Richard, S.; Gardie, B.; Couvé, S.; Gad, S. Von Hippel-Lindau: How a rare disease illuminates cancer biology. Semin. Cancer. Biol. 2013, 23, 26-37. [CrossRef]

8. Vortmeyer, A.O.; Falke, E.A.; Gläsker, S.; Li, J.; Oldfield, E.H. Nervous system involvement in von Hippel-Lindau disease: Pathology and mechanisms. Acta. Neuropathol. 2013, 125, 333-350. [CrossRef]

9. Neumann, H.P.H.; Bender, B.U.; Berger, D.P.; Laubenberger, J.; Schultze-Seemann, W.; Wetterauer, U.; Ferstl, F.J.; Herbst, E.W.; Schwarzkopf, G.; Hes, F.J.; et al. Prevalence, morphology and biology of renal cell carcinoma in von Hippel-Lindau disease compared to sporadic renal cell carcinoma. J. Urol. 1998, 160, 1248-1254. [CrossRef]

10. Bausch, B.; Jilg, C.; Gläsker, S.; Vortmeyer, A.; Lützen, N.; Anton, A.; Eng, C.; Neumann, H.P.H. Renal cancer in von Hippel-Lindau disease and related syndromes. Nat. Rev. Nephrol. 2013, 9, 529-538. [CrossRef]

11. Montani, M.; Heinimann, K.; Von Teichman, A.; Rudolph, T.; Perren, A.; Moch, H. VHL-gene deletion in single renal tubular epithelial cells and renal tubular cysts: Further evidence for a cyst-dependent progression pathway of clear cell renal carcinoma in von hippel-lindau disease. Am. J. Surg. Pathol. 2010, 34, 806-815. [CrossRef] [PubMed]

12. Joosten, S.C.; Smits, K.M.; Aarts, M.J.; Melotte, V.; Koch, A.; Tjan-Heijnen, V.C.; Van Engeland, M. Epigenetics in renal cell cancer: Mechanisms and clinical applications. Nat. Rev. Urol. 2018, 15, 430-451. [CrossRef] [PubMed]

13. Beroukhim, R.; Brunet, J.P.; Di Napoli, A.; Mertz, K.D.; Seeley, A.; Pires, M.M.; Linhart, D.; Worrell, R.A.; Moch, H.; Rubin, M.A.; et al. Patterns of gene expression and copy-number alterations in von-Hippel Lindau disease-associated and sporadic clear cell carcinoma of the kidney. Cancer Res. 2009, 69, 4674-4681. [CrossRef] [PubMed]

14. Capitanio, J.F.; Mazza, E.; Motta, M.; Mortini, P.; Reni, M. Corrigendum to “Mechanisms, indications and results of salvage systemic therapy for sporadic and von Hippel-Lindau related hemangioblastomas of the central nervous system" [Crit. Rev. Oncol. Hematol. 86 (2013) 69-84]. Crit. Rev. Oncol. Hematol. 2014, 90, 91. [CrossRef]

15. Jonasch, E.; McCutcheon, I.E.; Gombos, D.S.; Ahrar, K.; Perrier, N.D.; Liu, D.; Robichaux, C.C.; Villarreal, M.F.; Weldon, J.A.; Woodson, A.H.; et al. Pazopanib in patients with von Hippel-Lindau disease: A single-arm, single-centre, phase 2 trial. Lancet Oncol. 2018, 19, 1351-1359. [CrossRef] 
16. Albiñana, V.; De Las-Heras, K.V.G.; Serrano-Heras, G.; Segura, T.; Perona-Moratalla, A.B.; Mota-Pérez, M.; De Campos, J.M.; Botella, L.M. Propranolol reduces viability and induces apoptosis in hemangioblastoma cells from von Hippel-Lindau patients. Orphanet. J. Rare Dis. 2015, 10, 1-12. [CrossRef]

17. Cifola, I.; Bianchi, C.; Mangano, E.; Bombelli, S.; Frascati, F.; Fasoli, E.; Ferrero, S.; Di Stefano, V.; Zipeto, M.A.; Magni, F.; et al. Renal cell carcinoma primary cultures maintain genomic and phenotypic profile of parental tumor tissues. BMC Cancer 2011, 11, 244. [CrossRef]

18. Cuesta, A.M.; Albiñana, V.; Gallardo-Vara, E.; Recio-Poveda, L.; de Rojas-P, I.; de Las-Heras, K.V.G.; Aguirre, D.T.; Botella, L.M. The $\beta 2$-adrenergic receptor antagonist ICI-118,551 blocks the constitutively activated HIF signalling in hemangioblastomas from von Hippel-Lindau disease. Sci. Rep. 2019, 9, 10062. [CrossRef]

19. Albiñana, V.; Escribano, R.M.J.; Soler, I.; Padial, L.R.; Recio-Poveda, L.; De Las-Heras, K.V.G.; Botella, L.M. Repurposing propranolol as a drug for the treatment of retinal haemangioblastomas in von Hippel-Lindau disease. Orphanet. J. Rare. Dis. 2017, 12, 122. [CrossRef]

20. González-Rodríguez, B.; De Las-Heras, K.V.G.; Aguirre, D.T.; Rodríguez-Padial, L.; Albiñana, V.; Recio-Poveda, L.; Cuesta, A.M.; Botella, L.M.; Jiménez-Escribano, R.M. Evaluation of the safety and effectiveness of oral propranolol in patients with von Hippel-Lindau disease and retinal hemangioblastomas: Phase III clinical trial. BMJ. Open. Ophthalmol. 2019, 4, e000203. [CrossRef]

21. Treatment of Von Hippel-Lindau (VHL)-Related Hemangioblastoma With PTK787/ZK 222584. Available online: https://linicaltrials.gov/ct2/show/NCT00052013 (accessed on 31 May 2020).

22. Eyetech Study Group. Preclinical and phase 1A clinical evaluation of an anti-VEGF pegylated aptamer (EYE001) for the treatment of exudative age-related macular degeneration. Retina 2002, 22, 143-152. [CrossRef] [PubMed]

23. 17AAG to Treat Kidney Tumors in Von Hippel-Lindau Disease. Available online: https://clinicaltrials.gov/ ct2/show/results/NCT00088374 (accessed on 31 May 2020).

24. Wong, W.T.; Liang, K.J.; Hammel, K.; Coleman, H.R.; Chew, E.Y. Intravitreal ranibizumab therapy for retinal capillary hemangioblastoma related to von Hippel-Lindau disease. Ophthalmology 2008, 115, 1957-1964. [CrossRef] [PubMed]

25. Jonasch, E.; McCutcheon, I.E.; Waguespack, S.G.; Wen, S.; Davis, D.W.; Smith, L.A.; Tannir, N.M.; Gombos, D.S.; Fuller, G.N.; Matin, S.F. Pilot trial of sunitinib therapy in patients with von Hippel-Lindau disease. Ann. Oncol. 2011, 22, 2661-2666. [CrossRef] [PubMed]

26. Evaluation of Sunitinib Malate in Patients With Von Hippel-Lindau Syndrome (VHL) Who Have VHL Lesions to Follow. Available online: https://clinicaltrials.gov/ct2/show/results/NCT00330564 (accessed on 31 May 2020).

27. Phase II Study of Vandetanib in Individuals With Kidney Cancer. Available online: https:/clinicaltrials.gov/ ct2/show/results/NCT00566995 (accessed on 31 May 2020).

28. Knickelbein, J.E.; Jacobs-El, N.; Wong, W.T.; Wiley, H.E.; Cukras, C.A.; Meyerle, C.B.; Chew, E.Y. Systemic Sunitinib Malate Treatment for Advanced Juxtapapillary Retinal Hemangioblastomas Associated with von Hippel-Lindau Disease. Ophthalmol. Retin. 2017, 1, 181-187. [CrossRef] [PubMed]

29. Sunitinib Malate to Treat Advanced Eye Disease in Patients With Von Hippel-Lindau Syndrome (VHL3). Available online: https://clinicaltrials.gov/ct2/show/results/NCT00673816 (accessed on 31 May 2020).

30. Oudard, S.; Elaidi, R.; Brizard, M.; Le Rest, C.; Caillet, V.; Deveaux, S.; Benoit, G.; Corréas, J.M.; Benoudiba, F.; David, P.; et al. Sunitinib for the treatment of benign and malignant neoplasms from von Hippel-Lindau disease: A single-arm, prospective phase II clinical study from the PREDIR group. Oncotarget 2016, 7, 85306-85317. [CrossRef]

31. Welsh, S.; Fife, K.; Matakidou, A.; Mullin, J.; Machin, A.; Qian, W.; Ingleson, V.; Dalchau, K.M.; Whittaker, P.; Warren, A.; et al. A phase II clinical study evaluating the efficacy and safety of neoadjuvant and adjuvant sunitinib in previously untreated patients with metastatic renal cell carcinoma (mRCC) (NeoSun). J. Clin. Oncol. 2017, 35, e16087. [CrossRef]

32. Pilié, P.; Hasanov, E.; Matin, S.F.; Woodson, A.H.H.; Marcott, V.D.; Bird, S.; Slack, R.S.; Fuller, G.N.; McCutcheon, I.E.; Jonasch, E. Pilot study of dovitinib in patients with von Hippel-Lindau disease. Oncotarget 2018, 9, 23390-23395. [CrossRef]

33. TKI 258 in Von Hippel-Lindau Syndrome (VHL). Available online: https:/clinicaltrials.gov/ct2/show/results/ NCT01266070 (accessed on 31 May 2020). 
34. Jonasch, E.; Donskov, F.; Iliopoulos, O.; Rathmell, W.K.; Narayan, V.; Maughan, B.J.; Oudard, S.; Else, T.; Maranchie, J.K.; Welsh, S.J.; et al. Phase II study of the oral HIF- $2 \alpha$ inhibitor MK-6482 for Von Hippel-Lindau disease-associated renal cell carcinoma. J. Clin. Oncol. 2020, 38, 5003. [CrossRef]

35. Lobo, N.C.; Gedye, C.; Apostoli, A.J.; Brown, K.R.; Paterson, J.; Stickle, N.; Robinette, M.; Fleshner, N.; Hamilton, R.J.; Kulkarni, G.; et al. Efficient generation of patient-matched malignant and normal primary cell cultures from clear cell renal cell carcinoma patients: Clinically relevant models for research and personalized medicine. BMC Cancer 2016, 16, 485. [CrossRef]

36. Shepard, M.J.; Bugarini, A.; Edwards, N.A.; Lu, J.; Zhang, Q.; Wu, T.; Zhuang, Z.; Chittiboina, P. Repurposing propranolol as an antitumor agent in von Hippel-Lindau disease. J. Neurosurg. 2019, 131, 1106-1114. [CrossRef]

37. Yin, T.; Yu, S.; Xiao, L.; Zhang, J.; Liu, C.; Lu, Y.; Liu, C. Correlation between the expression of aquaporin 1 and hypoxia-inducible factor 1 in breast cancer tissues. J. Huazhong Univ. Sci. Technol. 2008, 28, 346-348. [CrossRef] [PubMed]

38. Abreu-Rodríguez, I.; Silva, R.S.; Martins, A.P.; Soveral, G.; Toledo-Aral, J.J.; López-Barneo, J.; Echevarría, M. Functional and transcriptional induction of aquaporin-1 gene by hypoxia; analysis of promoter and role of HIF-1 $\alpha$. PLoS ONE 2011, 6, e28385. [CrossRef] [PubMed]

39. Deb, P.; Pal, S.; Dutta, V.; Boruah, D.; Chandran, V.M.; Bhatoe, H.S. Correlation of expression pattern of aquaporin-1 in primary central nervous system tumors with tumor type, grade, proliferation, microvessel density, contrast-enhancement and perilesional edema. J. Cancer Res. Ther. 2012, 8, 571-577. [CrossRef] [PubMed]

40. Zhang, C.; Yang, C.; Feldman, M.J.; Wang, H.; Pang, Y.; Maggio, D.M.; Zhu, D.; Nesvick, C.L.; Dmitriev, P.; Bullova, P.; et al. Vorinostat suppresses hypoxia signaling by modulating nuclear translocation of hypoxia inducible factor 1 alpha. Oncotarget 2017, 8, 56110-56125. [CrossRef] [PubMed]

41. Bardwin, A.S. Control of oncogenesis and cancer therapy resistance by the transcription factor NF-kappaB. J. Clin. Investig. 2001, 107, 241-246. [CrossRef] [PubMed]

42. Malec, V.; Coulson, J.M.; Urbé, S.; Clague, M.J. Combined Analyses of the VHL and Hypoxia Signaling Axes in an Isogenic Pairing of Renal Clear Cell Carcinoma Cells. J. Proteome Res. 2015, 14, 5263-5272. [CrossRef]

43. Chang, P.Y.; Huang, W.Y.; Lin, C.L.; Huang, T.C.; Wu, Y.Y.; Chen, J.H.; Kao, C.H. Propranolol reduces cancer risk. Medicine 2015, 94, e1097. [CrossRef]

44. Wilding, A.; Ingham, S.L.; Lalloo, F.; Clancy, T.; Huson, S.M.; Moran, A.; Evans, D.G. Life expectancy in hereditary cancer predisposing diseases: An observational study. J. Med. Genet. 2012, 49, 264-269. [CrossRef]

45. Van Velthoven, V.; Reinacher, P.C.; Klisch, J.; Neumann, H.P.H.; Gläsker, S.; Bristol, R.E.; Spetzler, R.F.; Bricolo, A.; Benzel, E.C.; Lefranc, F.; et al. Treatment of Intramedullary Hemangioblastomas, with Special Attention to Von Hippel-Lindau Disease. Neurosurgery 2003, 53, 1306-1314. [CrossRef]

46. Giles, R.H.; Gläsker, S. The first prospective trial for von Hippel-Lindau disease: Pazopanib. Lancet Oncol. 2018, 19, 1267-1269. [CrossRef]

47. Gläsker, V.; Klingler, J.H. RareConnect.org Webinar: Hemangioblastomas of the Central Nervous System in Patients with VHL. Available online: https://youtu.be/F0wS19AQxrg (accessed on 26 November 2018).

48. Huang, Q.; Tan, Q.; Mao, K.; Yang, G.; Ma, G.; Luo, P.; Wang, S.; Mei, P.; Wu, F.; Xu, J.; et al. The role of adrenergic receptors in lung cancer. Am. J. Cancer. Res. 2018, 8, 2227-2237. [PubMed]

49. Xiao, M.B.; Jin, D.D.; Jiao, Y.J.; Ni, W.K.; Liu, J.X.; Qu, L.S.; Lu, C.H.; Ni, R.Z.; Jiang, F.; Chen, W.C. $\beta 2-A R$ regulates the expression of AKR1B1 in human pancreatic cancer cells and promotes their proliferation via the ERK1/2 pathway. Mol. Biol. Rep. 2018, 45, 1863-1871. [CrossRef]

50. Cui, B.; Luo, Y.; Tian, P.; Peng, F.; Lu, J.; Yang, Y.; Su, Q.; Liu, B.; Yu, J.; Luo, X.; et al. Stress-induced epinephrine enhances lactate dehydrogenase A and promotes breast cancer stem-like cells. J. Clin. Investig. 2019, 129, 1030-1046. [CrossRef] [PubMed]

51. De Giorgi, V.; Grazzini, M.; Benemei, S.; Marchionni, N.; Botteri, E.; Pennacchioli, E.; Geppetti, P.; Gandini, S. Propranolol for Off-label Treatment of Patients With Melanoma: Results From a Cohort Study. JAMA Oncol. 2018, 4, e172908. [CrossRef] [PubMed]

52. Pasquier, E.; Street, J.; Pouchy, C.; Carre, M.; Gifford, A.J.; Murray, J.; Norris, M.D.; Trahair, T.; Andre, N.; Kavallaris, M. $\beta$-blockers increase response to chemotherapy via direct antitumour and anti-angiogenic mechanisms in neuroblastoma. Br. J. Cancer 2013, 108, 2485-2494. [CrossRef] 
53. Phadke, S.; Clamon, G. Beta blockade as adjunctive breast cancer therapy: A review. Crit. Rev. Oncol. Hematol. 2019, 138, 173-177. [CrossRef]

54. Léauté-Labrèze, C.; De La Roque, E.D.; Hubiche, T.; Boralevi, F.; Thambo, J.B.; Taïeb, A. Propranolol for severe hemangiomas of infancy. N. Engl. J. Med. 2008, 358, 2649-2651. [CrossRef]

55. Lamy, S.; Lachambre, M.P.; Lord-Dufour, S.; Béliveau, R. Propranolol suppresses angiogenesis in vitro: Inhibition of proliferation, migration, and differentiation of endothelial cells. Vasc. Pharmacol. 2010, 53, 200-208. [CrossRef]

56. Storch, C.H.; Hoeger, P.H. Propranolol for infantile haemangiomas: Insights into the molecular mechanisms of action. Br. J. Dermatol. 2010, 163, 269-274. [CrossRef]

57. Wong, A.; Hardy, K.L.; Kitajewski, A.M.; Shawber, C.J.; Kitajewski, J.K.; Wu, J.K. Propranolol accelerates adipogenesis in hemangioma stem cells and causes apoptosis of hemangioma endothelial cells. Plast. Reconstr. Surg. 2012, 130, 1012-1021. [CrossRef]

58. Munabi, N.C.O.; England, R.W.; Edwards, A.K.; Kitajewski, A.A.; Tan, Q.K.; Weinstein, A.; Kung, J.E.; Wilcox, M.; Kitajewski, J.K.; Shawber, C.J.; et al. Propranolol Targets Hemangioma Stem Cells via cAMP and Mitogen-Activated Protein Kinase Regulation. Stem Cells Transl. Med. 2016, 5, 45-55. [CrossRef] [PubMed]

59. Chen, L.; Xia, G.; Qiu, F.; Wu, C.; Denmon, A.P.; Zi, X. Physapubescin selectively induces apoptosis in VHL-null renal cell carcinoma cells through down-regulation of HIF-2 $\alpha$ and inhibits tumor growth. Sci. Rep. 2016, 6, 32582. [CrossRef] [PubMed]

60. Di Cristofano, C.; Minervini, A.; Menicagli, M.; Salinitri, G.; Bertacca, G.; Pefanis, G.; Masieri, L.; Lessi, F.; Collecchi, P.; Minervini, R.; et al. Nuclear expression of hypoxia-inducible factor- $1 \alpha$ in clear cell renal cell carcinoma is involved in tumor progression. Am. J. Surg. Pathol. 2007, 31, 1875-1881. [CrossRef] [PubMed]

61. Uniacke, J.; Holterman, C.E.; Lachance, G.; Franovic, A.; Jacob, M.D.; Fabian, M.R.; Payette, J.; Holcik, M.; Pause, A.; Lee, S. An oxygen-regulated switch in the protein synthesis machinery. Nature 2012, 486, 126-129. [CrossRef] [PubMed]

62. Yang, H.; Minamishima, Y.A.; Yan, Q.; Schlisio, S.; Ebert, B.L.; Zhang, X.; Zhang, L.; Kim, W.Y.; Olumi, A.F.; Kaelin, W.G., Jr. pVHL acts as an adaptor to promote the inhibitory phosphorylation of the NF-kappaB agonist Card9 by CK2. Mol. Cell 2007, 28, 15-27. [CrossRef] [PubMed]

63. Van Uden, P.; Kenneth, N.S.; Rocha, S. Regulation of hypoxia-inducible factor-1 $\alpha$ a by NF-кB. Biochem. J. 2008, 412, 477-484. [CrossRef]

64. Díaz-Castellanos, M.A.; Gómez de las Heras, K.V.; Díaz-Redondo, T.; González-Flores, E.; Albiñana, V.; Botella, L.M. Case Report: Propranolol increases the therapeutic response to temozolomide in a patient with metastatic paraganglioma. F1000Research 2017, 6, 2087. [CrossRef]

65. Lu, Y.; Xu, Q.; Zuo, Y.; Liu, L.; Liu, S.; Chen, L.; Wang, K.; Lei, Y.; Zhao, X.; Li, Y. Isoprenaline/ $\beta 2-A R$ activates Plexin-A1/VEGFR2 signals via VEGF secretion in gastric cancer cells to promote tumor angiogenesis. BMC Cancer 2017, 17, 875. [CrossRef]

(C) 2020 by the authors. Licensee MDPI, Basel, Switzerland. This article is an open access article distributed under the terms and conditions of the Creative Commons Attribution (CC BY) license (http://creativecommons.org/licenses/by/4.0/). 